\title{
A Framework for Analyzing Monetary Policy in an Economy with E-money
}

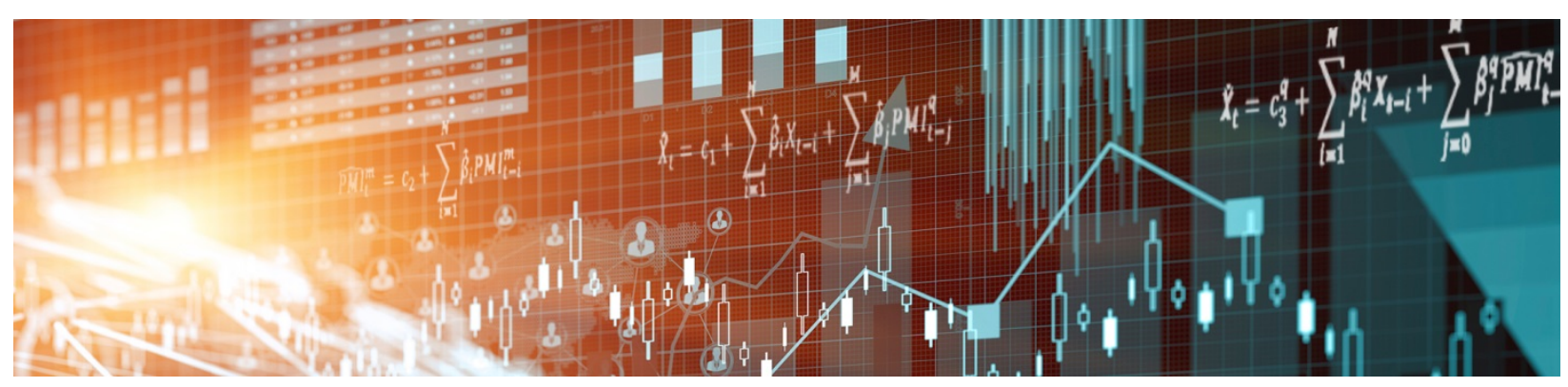

by Yu Zhu and Scott Hendry 
Bank of Canada Staff Working Paper 2019-1

January 2019

\title{
A Framework for Analyzing Monetary Policy in an Economy with E-money
}

\author{
by \\ Yu Zhu and Scott Hendry \\ Funds Management and Banking Department \\ Bank of Canada \\ Ottawa, Ontario, Canada K1A 0G9 \\ yuzhu@bankofcanada.ca \\ shendry@bankofcanada.ca
}




\section{Acknowledgements}

We are very grateful to Charles Kahn for his invaluable comments. We thank Jonathan Chiu, Mohammad Davoodalhosseini, Janet Jiang, Harald Uhlig, Russell Wong and Randall Wright for their helpful comments. The views expressed in this paper are those of the authors. No responsibility for them should be attributed to the Bank of Canada. 


\begin{abstract}
This paper considers an economy where central-bank-issued fiat money competes with privately issued e-money. We study a policy-setting game between the central bank and the e-money issuer and find (1) the optimal monetary policy of the central bank depends on the policy of the private issuer and may deviate from the Friedman rule; (2) there may exist multiple equilibria; (3) when the economy approaches a cashless state, the central bank's optimal policy improves the market power of the e-money issuer and can lead to a discrete decrease in welfare and a discrete increase in inflation; and (4) first best cannot be achieved. Central-bank-issued e-money leads to a simple optimal policy that achieves the first best.
\end{abstract}

Bank topics: Digital currencies; Monetary policy

JEL code: E52

\title{
Résumé
}

Dans cette étude, nous analysons une économie où la monnaie fiduciaire émise par la banque centrale est en concurrence avec la monnaie électronique émise par une entité privée. Nous étudions les issues d'un jeu dans lequel la banque centrale et l'émetteur de monnaie électronique établissent leur propre politique et faisons une série de constats. 1) La politique monétaire optimale de la banque centrale dépend de la politique de l'émetteur privé et peut s'écarter de la règle de Friedman. 2) Il pourrait exister des équilibres multiples. 3) Lorsque l'économie fonctionne presque sans numéraire, la politique optimale de la banque centrale accroît le pouvoir de marché de l'émetteur de monnaie électronique et peut entrainer un léger recul du bien-être ainsi qu'une hausse minime de l'inflation. 4) L'optimum de premier rang ne peut être atteint. La monnaie électronique émise par la banque centrale donne lieu à une politique optimale simple qui permet d'atteindre l'optimum de premier rang.

Sujets : Monnaies numériques; Politique monétaire

Code JEL : E52 


\section{Non-technical Summary}

We study the question of whether a central bank should issue its central bank digital currency from a monetary policy perspective. We consider an economy where central-bank-issued fiat money competes with privately issued e-money. The central bank controls monetary policy for fiat money while the e-money issuer decides the policy for e-money. We investigate how the wide adoption of e-money affects the central bank's optimal monetary policy and total welfare.

Results show that declining fiat money usage can hurt social welfare because the e-money issuer has an incentive to maximize its own profit instead of social welfare, and declining fiat money usage gives more monopoly power to the e-money issuer. If fiat money usage drops below a threshold, there can be a discrete drop in social welfare and then the optimal policy of the central bank depends on the e-money issuer's policy. This would add another complication to the monetary policy of the central bank. Issuing central bank digital currency can simplify the optimal policy of the central bank and improve the social welfare if it is designed to be a perfect substitute of the privately issued e-money. 


\section{Introduction}

Recently, there has been a heated discussion among several central banks on whether a central bank should issue its own e-money (central bank digital currency or CBDC). One important question in this discussion is whether a CBDC can be beneficial from a monetary policy perspective. This paper tries to provide some insights into this question by analyzing an economy where a privately issued e-money competes with central-bank-issued fiat money.

The e-money considered in this paper has four key features. First, it is widely accessible and may be used as a means of payment that competes with the fiat money. Second, it has advantages in certain transactions, such as transactions made online. For example, under the current technology of e-money, payment online is fast, no intermediaries are involved, and anonymity is partially retained. Third, the value of the e-money is not tied to the fiat money. Lastly, the private issuer has monopoly power and fully controls the monetary policy of e-money. We abstract from technological details such as block-chain technology and public ledger. ${ }^{1}$

We focus on a policy-setting game where the central bank maximizes total welfare and the e-money issuer maximizes its seigniorage income. We consider both the case where two issuers move simultaneously and the case where the central bank leads. The former is more suitable if the central bank cannot commit to not responding to the private issuer, while the latter is more suitable if the central bank can commit. In both cases, the first best is not achieved and the optimal policy of the central bank may deviate from the Friedman rule. The latter happens if usage of the fiat money becomes sufficiently low, i.e., the economy approaches cashless. Furthermore, if the central bank cannot commit, there can be a large drop in welfare if the usage of fiat money falls below a certain threshold.

\footnotetext{
${ }^{1}$ For discussions on the economics of the technology, see Chiu and Koeppl (2017), Biais et al. (2017) and Huberman et al. (2017).
} 
Intuitively, if the e-money issuer is not running the Friedman rule, the central bank faces the following trade-off. On the one hand, it wants to maintain the value of the fiat money by keeping low inflation in case households want to use the fiat money for transactions. On the other hand, it wants to encourage households to use e-money for transactions where e-money has an advantage. This can be achieved by raising inflation in fiat money since it is a substitute for e-money. The incentive to raise inflation would dominate if the usage of fiat money was sufficently low. In that case, the central bank would want to deviate from the Friedman rule.

If the central bank cannot commit to not responding to the e-money issuer, there is a strategic complementarity. E-money issuers want inflation in e-money to raise seigniorage income. The central bank then inflates fiat money to encourage usage of e-money. This makes fiat money less attractive and gives more market power to the e-money issuer. The e-money issuer responds by further increasing inflation in e-money. If the fiat money usage is not too low, there exists a high welfare and low inflation equilibrium where the central bank runs the Friedman rule and a low welfare and high inflation equilibrium where both issuers deviate from the Friedman rule. If fiat money usage falls below a threshold, the high welfare equilibrium disappears because the welfare gain from a better fiat money is too low. Then the equilibrium jumps to the low welfare equilibrium and causes a dramatic drop in welfare and a discrete increase in inflation. If the central bank can commit, the problem is less severe, but the central bank still has to take the e-money issuer's action into account and the optimal policy deviates from the Friedman rule when the economy approaches a cashless state.

These findings highlight the challenges that a central bank would face from privately issued e-money, especially in a cashless environment. First, the first best is not achieved and total welfare may drop dramatically if the usage of fiat money falls below some threshold. Second, the central bank monetary policy becomes more com- 
plicated because it has to take the response of the e-money issuer into account. If, however, the central bank issues a central bank e-money (CBDC), which is designed to be a perfect substitute for the private e-money, it can achieve the first best by running the Friedman rule for both monies. The CBDC crowds out the privately issued e-money because the private issuer cannot compete without incurring a loss. The CBDC simplifies the monetary policy and improves the welfare, especially when the economy is close to cashless.

This paper contributes to the growing literature on e-money. It is closely related to Fernández-Villaverde and Sanchez (2016), and Schilling and Uhlig (2018). The former analyzes privately issued e-money in a version of Lagos and Wright (2005). However, they focus on competition among privately issued monies and price stability. The latter focuses on bitcoin and studies price stability issues and how central bank monetary policy can stabilize the price of e-money. We focus on the steady state equilibrium and study optimal monetary policy from the welfare point of view. ${ }^{2}$

This paper is closely related to Lagos and Zhang (2018), who show that the central bank monetary policy stays effective even if the economy becomes close to cashless. This is because the fiat money provides an outside option and hence can discipline agents' behaviors even if it is not used. Similar to their work, central bank policy in our model stays effective by restricting the market power of the e-money issuer. However, we show that even if the central bank tries to maximize welfare, it may want to strengthen the e-money issuers' market power to some extend if fiat money usage is below some threshold. As a result, a declining usage of fiat money still has a negative effect on the economy.

Our work is also related to the large literature on international currency and competing currencies based on search theory. ${ }^{3}$ Among them, it is most related to

\footnotetext{
${ }^{2}$ Other papers studying privately issued e-money include Saito (2014) and Hendrickson et al. (2016). For an analysis of central-bank-issued e-money, see Davoodalhosseini (2018).

${ }^{3}$ An incomplete list includes Chang (1994); Uribe (1997); Engineer (2000); Ravikumar and Wallace (2002); Curtis and Waller (2000); Camera et al. (2004); Martin (2006) and Kahn (2013);
} 
Zhang (2014), who studies the adoption decision of foreign money and monetary policy competition between two countries. She also shows that optimal monetary policy may deviate from the Friedman rule because of the incentive to tax foreigners holding domestic money. In our model, the mechanism is different because we do not have foreign agents.

More generally, this paper contributes to the literature on liquid assets by showing that the Friedman rule may not be optimal if the liquid asset (e-money) and fiat money are substitutes. An incomplete list of papers that discuss liquid assets includes Geromichalos and Herrenbrueck (2016, 2017); Lester et al.(2012); Williamson (2012); Venkateswaran and Wright (2013); Li and Li (2013); Han (2015); He et al. (2015) and Rocheteau et al. (2016). This paper also makes a technical contribution by developing a fast and stable method to numerically solve models with two monies.

The rest of the paper is organized as follows. Section 2 lays out the environment of the model. Section 3 studies the steady state equilibrium and derives the comparative statics given the policies of the central bank and the e-money issuer. Section 4 analyzes the optimal monetary policy of the central bank if the e-money issuer's policy is exogenous. Section 5 considers a policy-setting game where both issuers move simultaneously. Section 6 discusses the scenario where the central bank moves first and the e-money issuer follows. Section 7 discusses various extensions of the baseline model. Section 8 concludes.

\section{Benchmark Model}

Time is discrete and continues forever. There is a continuum of households and a continuum of entrepreneurs. As in the standard New Monetarist model, at each date $t$, agents interact sequentially in two settings: a frictional decentralized market

Zhou (1997); Trejos and Wright (1996); Trejos (2003); Head and Shi (2003); Camera and Winkler (2003); Li and Matsui (2009); Liu and Shi (2010) and Zhang (2014). 
$(\mathrm{DM})$; and a frictionless centralized market $(\mathrm{CM})$.

In the DM, households want to consume a non-storable good $y$ and entrepreneurs can produce it on the spot. Households and entrepreneurs meet and trade bilaterally. Because of the lack of commitment and anonymity, no credit is viable. There is central-bank-issued intrinsically worthless fiat money $m$, and a worthless digital object $h$, which we refer to as e-money. The total supplies of fiat money and e-money at period $t$ are $M_{t}$ and $H_{t}$, respectively. They may be used as means of payment. Entrepreneurs may be one of three permanent types. With $\alpha_{1}$ probability, a household meets a type 1 entrepreneur, who accepts only the fiat money. With $\alpha_{2}$ probability, a household meets a type 2 entrepreneur, who does not accept the fiat money, but may accept the e-money. With $\alpha_{3}$ probability, a household meets a type 3 entrepreneur, who accepts both. ${ }^{4}$ One interpretation is that these entrepreneurs offer the same product but operate in different locations. Type 1 entrepreneurs do not have access to the internet and have to rely on fiat money. Type 2 entrepreneurs specialize in online trading and e-money is more convenient. Type 3 entrepreneurs operate local stores but also have access to the internet. Therefore, they can accept both. Another interpretation is that these entrepreneurs sell different products. In particular, type 1 firms are government agencies providing services and accept only fiat money. ${ }^{5}$ Then we can interpret the $\alpha$ s as the probability that a household needs to consume the corresponding product. In either case, a household meets an entrepreneur at most once in the DM each period. And if no trade occurs, he proceeds to the next $\mathrm{CM}$.

In the CM, both households and entrepreneurs consume a numeraire good $x$, supply labor $\ell$, trade $m$ and $h$. Households do not know which type of entrepreneurs they will meet in the next DM. Hence, they would hold both monies to insure

\footnotetext{
${ }^{4}$ The exchange rate between the fiat money and e-money is determined in the equilibrium.

${ }^{5}$ If we take this interpretation, we implicitly assume that the cost functions and the utility functions are the same across all three products. However, all of the following analysis remains valid if the utility and cost vary across products.
} 
themselves against different transaction needs. Both households and entrepreneurs have access to a technology that translates labor to the numeraire good one-for-one. The central bank and the e-money issuer control $M_{t}$ and $H_{t}$, respectively. They do so by buying or selling their own monies in the centralized market. Any loss or income is given back to households through lump-sum transfer or tax. The government has a consolidated budget constraint with a passive fisal policy. Therefore, the central bank has the resources to sustain a negative money growth rate. If the e-money issuer cannot finance losses, the growth rate of e-money can be only non-negative. Denote the growth rate of the fiat money as $\mu_{t+1}^{m}=M_{t+1} / M_{t}-1$ and that of e-money as $\mu_{t+1}^{h}=H_{t+1} / H_{t}-1$. In the next two sections, we treat them as exogenous and study the outcome of the economy. Sections 4-6 endogenize $\mu_{t+1}^{m}$ and $\mu_{t+1}^{h}$.

The lifetime utility for the households is $\sum_{t=1} \beta^{t}\left[U\left(x_{t}\right)-\ell_{t}+u\left(y_{t}\right)\right]$, where $u$ and $U$ satisfy the usual monotonicity and curvature conditions. In addition, $u^{\prime \prime}$ is continuous and bounded at any $y>0$. Similarly, entrepreneurs have lifetime utility $\sum_{t=1} \beta^{t}\left[U\left(x_{t}\right)-\ell_{t}-c\left(y_{t}\right)\right]$, where $c^{\prime \prime}$ is strictly postive and bounded away from $\infty$ on any finite interval.

The CM problem for a household is

$$
\begin{aligned}
W_{t}^{H}\left(m_{t}, h_{t}\right) & =\max _{x_{t}, \ell_{t}, \hat{m}_{t+1}, \hat{h}_{t+1}} U\left(x_{t}\right)-\ell_{t}+\beta V_{t+1}^{H}\left(\hat{m}_{t+1}, \hat{h}_{t+1}\right), \\
\text { s.t. } x & =\phi_{t}\left(m_{t}-\hat{m}_{t+1}\right)+\psi_{t}\left(h_{t}-\hat{h}_{t+1}\right)+\ell_{t}+T_{t},
\end{aligned}
$$

where $V_{t+1}^{H}$ is the LW market value function in period $t+1 ; \hat{m}_{t+1}$ and $\hat{h}_{t+1}$ are the amount of fiat money and e-money that the household brings into the next DM; and $\phi_{t}$ and $\psi_{t}$ are the prices of fiat money and e-money in terms of the numeraire good $x$. If any of them equals 0 , the corresponding money is not adopted. The first-order 
conditions (FOCs) are

$$
\begin{aligned}
\hat{m}_{t+1}: & \phi_{t}=\beta \frac{\partial}{\partial \hat{m}_{t+1}} V_{t+1}^{H}\left(\hat{m}_{t+1}, \hat{h}_{t+1}\right), \\
\hat{h}_{t+1} & : \quad \psi_{t}=\beta \frac{\partial}{\partial \hat{h}_{t+1}} V_{t+1}^{H}\left(\hat{m}_{t+1}, \hat{h}_{t+1}\right), \\
x_{t} & : \quad 1=U^{\prime}\left(x_{t}\right) .
\end{aligned}
$$

Envelope conditions are

$$
\frac{\partial}{\partial m_{t}} W_{t}^{H}\left(m_{t}, h_{t}\right)=\phi_{t}, \frac{\partial}{\partial h_{t}} W_{t}^{H}\left(m_{t}, h_{t}\right)=\psi_{t} .
$$

Because an entrepreneur does not need to consume in the DM, he does not take any money out of the CM. Then his CM problem is

$$
\begin{aligned}
W_{t}^{E}\left(m_{t}, h_{t}\right) & =\max _{x_{t}, \ell_{t}} U\left(x_{t}\right)-\ell_{t}+\beta V_{t+1}^{E}(0,0) \\
\text { s.t. } x_{t} & =\phi_{t} m_{t}+\psi_{t} h_{t}+\ell_{t}+T_{t} .
\end{aligned}
$$

The FOC is $U^{\prime}\left(x_{t}\right)=1$ and the envelope conditions are the same as in (4).

The DM value function for a household is

$$
\begin{aligned}
V_{t}^{H}\left(m_{t}, h_{t}\right)= & \alpha_{1}\left[u\left(y_{t}^{1}\right)+W_{t}^{H}\left(m_{t}-m_{t}^{1}, h_{t}\right)\right]+\alpha_{2}\left[u\left(y_{t}^{2}\right)+W_{t}^{H}\left(m_{t}, h_{t}-h_{t}^{2}\right)\right] \\
& +\alpha_{3}\left[u\left(y_{t}^{3}\right)+W_{t}^{H}\left(m_{t}-m_{t}^{3}, h_{t}-h_{t}^{3}\right)\right]+\left(1-\sum_{i=1}^{3} \alpha_{i}\right) W_{t}^{H}\left(m_{t}, h_{t}\right) .
\end{aligned}
$$

where $y_{t}^{i}, i=1,2,3$ are consumptions in different types of trades and $m_{t}^{1}, h_{t}^{2}, h_{t}^{3}$ and $m_{t}^{3}$ are corresponding payments. For example, with $\alpha_{1}$ probability, a household meets a type 1 entrepreneur. In this case, he needs to pay $m_{t}^{1}$ fiat money for $y_{t}^{1} \mathrm{DM}$ consumption. In the next $\mathrm{CM}$, he has only $m_{t}-m_{t}^{1}$ fiat money left. By the envelope conditions (4), $W_{t}^{H}$ is linear in both $m_{t}$ and $h_{t}$. We can rewrite as follows:

$$
\begin{aligned}
V_{t}^{H}\left(m_{t}, h_{t}\right)= & \alpha_{1}\left[u\left(y_{t}^{1}\right)-\phi_{t} m_{t}^{1}\right]+\alpha_{2}\left[u\left(y_{t}^{2}\right)-\psi_{t} h_{t}^{2}\right] \\
& +\alpha_{3}\left[u\left(y_{t}^{3}\right)-\psi_{t} h_{t}^{3}-\phi_{t} m_{t}^{3}\right]+W_{t}^{H}\left(m_{t}, h_{t}\right) .
\end{aligned}
$$


Consumptions and payments are determined by the Kalai bargaining solution. ${ }^{6}$ Let $y^{*}$ be the efficient DM consumption which satisfies $u^{\prime}\left(y^{*}\right)=c^{\prime}\left(y^{*}\right)$ and $g(y)=$ $\theta y+(1-\theta) u(y)$, where $\theta$ is the bargaining power to the buyer. Let $z$ be the total real balances that a household can use in a transaction. The corresponding terms of trade are $y=Y(z)$ and $p=P(z)$,

$$
Y(z)=\left\{\begin{array}{cc}
g^{-1}(z) & \text { if } z<z^{*} \\
y^{*} & \text { otherwise }
\end{array} \text { and } P(z)=\left\{\begin{array}{cc}
z & \text { if } z<z^{*} \\
z^{*} & \text { otherwise }
\end{array}\right.\right.
$$

where $p$ is payment in real terms and $z^{*}=\theta c\left(y^{*}\right)+(1-\theta) u\left(y^{*}\right)$.

Then we can take partial derivatives of (5) and use (6) to obtain the envelope conditions of the DM value function

$$
\begin{aligned}
\frac{\partial}{\partial m_{t}} V_{t}^{H}\left(m_{t}, h_{t}\right) & =\alpha_{1} \lambda\left(\phi_{t} m_{t}\right) \phi_{t}+\alpha_{3} \lambda\left(\phi_{t} m_{t}+\psi_{t} h_{t}\right) \phi_{t}+\beta \phi_{t} \\
\frac{\partial}{\partial h_{t}} V_{t}^{H}\left(m_{t}, h_{t}\right) & =\alpha_{2} \lambda\left(\psi_{t} h_{t}\right) \psi_{t}+\alpha_{3} \lambda\left(\phi_{t} m_{t}+\psi_{t} h_{t}\right) \psi_{t}+\beta \psi_{t}
\end{aligned}
$$

where $\lambda$ is the liquidity premium defined as

$$
\lambda(z)=\left\{\begin{array}{cl}
\frac{u^{\prime}}{g^{\prime}} \circ g^{-1}(z)-1>0 & \text { if } z<D^{*} \\
0 & \text { if } z \geq D^{*}
\end{array} .\right.
$$

It captures the fact that more money relaxes the liquidity constraint in the DM and enables households to consume more. A formal derivation of (7)-(8) is provided in Appendix A. Combine them with (1) to obtain the Euler equations

$$
\begin{aligned}
& \phi_{t}=\alpha_{1} \beta \lambda\left(\phi_{t+1} \hat{m}_{t+1}\right) \phi_{t+1}+\alpha_{3} \beta \lambda\left(\phi_{t+1} \hat{m}_{t+1}+\psi_{t+1} \hat{h}_{t+1}\right) \phi_{t+1}+\beta \phi_{t+1} \\
& \psi_{t}=\alpha_{2} \beta \lambda\left(\psi_{t+1} \hat{h}_{t+1}\right) \psi_{t+1}+\alpha_{3} \beta \lambda\left(\phi_{t+1} \hat{m}_{t+1}+\psi_{t+1} \hat{h}_{t+1}\right) \psi_{t+1}+\beta \psi_{t+1} .
\end{aligned}
$$

Define $z_{t}^{m}=\phi_{t} M_{t}, z_{t}^{h}=\psi_{t} H_{t}$ and use the market clearing conditions $\hat{m}_{t+1}=$ $M_{t+1}$ and $\hat{h}_{t+1}=H_{t+1}$ to obtain

$$
\begin{aligned}
\left(1+\mu_{t+1}^{m}\right) z_{t}^{m} & =\alpha_{1} \beta \lambda\left(z_{t+1}^{m}\right) z_{t+1}^{m}+\alpha_{3} \beta \lambda\left(z_{t+1}^{m}+z_{t+1}^{h}\right) z_{t+1}^{m}+\beta z_{t+1}^{m} \\
\left(1+\mu_{t+1}^{h}\right) z_{t}^{h} & =\alpha_{2} \beta \lambda\left(z_{t+1}^{h}\right) z_{t+1}^{h}+\alpha_{3} \beta \lambda\left(z_{t+1}^{m}+z_{t+1}^{h}\right) z_{t+1}^{h}+\beta z_{t+1}^{h} .
\end{aligned}
$$

\footnotetext{
${ }^{6}$ The results derived in this paper do not depend on the Kalai solution. They also hold under other solution concepts such as Walrasian pricing and a strategic bargain game analyzed in Zhu (2018).
} 
Any non-negative sequence $\left\{\left(z_{t}^{m}, z_{t}^{h}\right)\right\}_{t=1}^{\infty}$ that solves (10) and (11) constitutes an equilibrium if it satisfies the transversality conditions $\lim _{t \rightarrow \infty} \beta^{t} z_{t}^{m}=0$ and $\lim _{t \rightarrow \infty} \beta^{t} z_{t}^{h}=$ 0 . The liquidity premium $\lambda$ is essentially the Lagrangian multiplier on the constraint that households cannot spend more than they have. If the constraint is binding, $\lambda$ is strictly positive and the household spends everything. Otherwise, $\lambda=0$ and the household consumes $y^{*}$.

\section{Steady State Equilibrium}

Now we study the steady state equilibrium given the constant money growth rates, i.e., $\mu_{t}^{m}=\mu^{m}$ and $\mu_{t}^{h}=\mu^{h}$ for all $t$. In the steady state, $z_{t}^{m}$ and $z_{t}^{h}$ stay constant over time and the inflation rates $\pi^{m}=\phi_{t} / \phi_{t+1}-1$ and $\pi^{h}=\psi_{t} / \psi_{t+1}-1$ equal the money growth rates, i.e., $\pi^{m}=\mu^{m}$ and $\pi^{h}=\mu^{h}$. There always exist equilibria where either or both of the monies are not valued due to self-fulfilling prophecies. Since our goal is to analyze the interaction between the two monies, we focus the equilibrium where a money is valued if it can be valued. Then equilibrium conditions reduce to

$$
\begin{aligned}
& i^{m} \geq \alpha_{1} \lambda\left(z^{m}\right)+\alpha_{3} \lambda\left(z^{m}+z^{h}\right) \text { strict inequality if } z^{m}=0, \\
& i^{h} \geq \alpha_{2} \lambda\left(z^{h}\right)+\alpha_{3} \lambda\left(z^{m}+z^{h}\right) \text { strict inequality if } z^{h}=0 .
\end{aligned}
$$

Here $i^{m}=\left(1+\pi^{m}\right) / \beta-1$ and $i^{h}=\left(1+\pi^{h}\right) / \beta-1$ are the nominal interest rates of illiquid nominal bonds in the corresponding monies, which is determined by the Fisher equation. In each of the equations, the left-hand side is the marginal cost of money, i.e., the forgone interest rate. The right-hand side is the marginal benefit of money, i.e., it enbles more consumption. A money is not valued if the marginal cost outweighs the marginal benefit. Otherwise, households bring in enough money such that its marginal cost equals marginal benefit.

In principle, the equilibrium can have four regimes: (1) no monies are valued; (2) only fiat money is valued; (3) only e-money is valued; and (4) both monies are 
valued. Regime 1 occurs iff $i^{m} \geq\left(\alpha_{1}+\alpha_{3}\right) \lambda(0)$ and $i^{h} \geq\left(\alpha_{2}+\alpha_{3}\right) \lambda(0)$, i.e., the cost of holding either money exceeds the benefit. In regime 2, holding e-money is too costly given that the fiat money is valued. This implies $i^{h} \geq \bar{\imath}^{h} \equiv \alpha_{2} \lambda(0)+\alpha_{3} \lambda\left(\bar{z}^{m}\right)$ where

$$
i^{m}=\alpha_{1} \lambda\left(\bar{z}^{m}\right)+\alpha_{3} \lambda\left(\bar{z}^{m}\right)
$$

or equivalently

$$
i^{h} \geq \bar{\imath}^{h}=\alpha_{2} \lambda(0)+\frac{\alpha_{3}}{\alpha_{1}+\alpha_{3}} i^{m}
$$

Symmetrically, in regime 3,

$$
i^{m} \geq \bar{\imath}^{m}=\alpha_{1} \lambda(0)+\frac{\alpha_{3}}{\alpha_{2}+\alpha_{3}} i^{h}
$$

Lastly, regime 4 happens only if $i^{m}<\bar{\imath}^{m}$ and $i^{h}<\bar{\imath}^{h}$.

Proposition 1 Equations (12)-(13) defines a unique equilibrium which satisfies

1. No money is valued iff $i^{m} \geq\left(\alpha_{1}+\alpha_{3}\right) \lambda(0)$ and $i^{h} \geq\left(\alpha_{2}+\alpha_{3}\right) \lambda(0)$.

2. Only fiat money is valued iff $i^{m}<\left(\alpha_{1}+\alpha_{3}\right) \lambda(0)$ and $i^{h} \geq \bar{\imath}^{h}$.

3. Only e-money is valued iff $i^{h}<\left(\alpha_{2}+\alpha_{3}\right) \lambda(0)$ and $i^{m} \geq \bar{\imath}^{m}$.

4. Both monies are valued iff $i^{m}<\bar{\imath}^{m}$ and $i^{h}<\bar{\imath}^{h}$.

Proof. See Appendix B.

Proposition 1 shows that only one of the four regimes can occur under any set of parameters. Given the fiat money is valued, Proposition 1(2) suggests that e-money can be valued iff $i^{h}<\bar{\imath}^{h}$. This condition is more likely to hold if $i^{m}$ is high and/or $\alpha_{2}$, the size of online trading, is large. It implies that if $\alpha_{2}$ is not too big, the central bank can deter the adoption of e-money by setting a low inflation or a low nominal interest rate. 
Proposition 2 The comparative statics are shown in Table 1.

\begin{tabular}{c|ccccc}
\hline \hline & $i^{m}$ & $i^{h}$ & $\alpha_{1}$ & $\alpha_{2}$ & $\alpha_{3}$ \\
\hline$z^{m}$ & - & + & + & - & + \\
$z^{h}$ & + & - & - & + & + \\
$\varphi$ & + & 0 & - & + & + \\
\hline
\end{tabular}

Table 1: Comparative Statics

Proof. See Appendix C.

Figure 1(a) shows the comparative statics with respect to $\alpha_{2}$. As $\alpha_{2}$ increases, e-money becomes more useful. Households demand more e-money, which raises its value and real balances $z^{h}$. Because e-money and fiat money are perfect substitutes in type 3 transactions, households demand less fiat money. This decreases the value of fiat money and its real balances $z^{m}$. This change translates to the change in adoption. Figure 1(b) plots three measures of adoption. The blue curve is the real balances of e-money as a fraction of total real balances in the economy, i.e., $z^{h} /\left(z^{m}+z^{h}\right)$. The red curve is the value of transactions made in e-money as a fraction of total transaction value. ${ }^{7}$ The magenta line is the same measure but only uses type 3 transactions. All three measures increase with $\alpha_{2}$. The central bank can restrict the adoption of e-money by requiring buyers and sellers to use fiat money, which increases $\alpha_{1}$ and decreases $\alpha_{2}$ and $\alpha_{3}$. It can achieve this goal by setting a low nominal interest rate. In particular, if $i^{m}=0$, households do not need to use e-money in type 3 transactions and e-money is a niche money that serves only type 2 transactions.

The presence of e-money can greatly reduce the central bank's ability to raise seigniorage income (inflation tax), because the demand for fiat money becomes more elastic. Figure 1(c) plots the seigniorage income of the central bank as a function

\footnotetext{
${ }^{7}$ Strictly speaking, there is a well-known indeterminacy here. Agents are indifferent between using fiat money or e-money in type 3 transactions. We assume that agents do not use e-money unless it is necessary. This can be justified by an arbitrarily small cost of adopting e-money in type 3 transactions.
} 


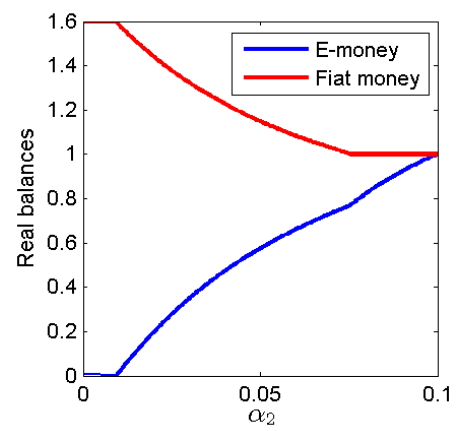

(a) Example 1: Real Balances



(b) Example 1: Adoption

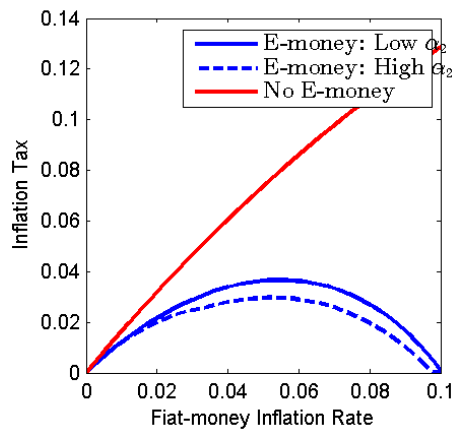

(c) Example 1: Inflation Tax

Figure 1: Effects of the Size of Type 2 Trades

of inflation rate in a numeric example. Parameters are shown in Table 2. The red curve is constructed under $\alpha_{2}=0$. And the two blue curves are constructed with $\alpha_{2}=0.01$ and 0.02 . With the introduction of e-money, seigniorage income decreases dramatically at any level of inflation. In addition, the seigniorage income is maximized at a much lower inflation rate. Therefore, existence of e-money can discipline the central bank.

\section{Optimal Monetary Policy: Exogenous $i^{h}$}

This section investigates the optimal monetary policy of the central bank when emoney grows at an exogenous rate $\mu^{h}$. The policy variable of the central bank is the time-invariant long-run money growth rates $\mu^{m}$. Since we focus on the steady state equilibrium, setting $\mu^{m}$ is equivalent to setting nominal interest rate $i^{m}$ under an exogenous $i^{h}$. This excerise is interesting for two reasons. First, e-money, like bitcoin, employs an exogenous long-run growth rate. Therefore, it is interesting to investigate how the central bank should respond. Second, this analysis helps to trace out the central bank's best response to $i^{h}$, which is later used to analyze a policy-setting game.

The central bank is benevolent and maximizes the total welfare of the economy, 
which includes type 2 transactions. ${ }^{8}$ The total welfare can be written as

$$
\begin{aligned}
\Omega\left(i^{m}, i^{h}\right)= & \alpha_{1}\left[u \circ y\left(z^{m}\right)-c \circ y\left(z^{m}\right)\right]+\alpha_{2}\left[u \circ y\left(z^{h}\right)-c \circ y\left(z^{h}\right)\right] \\
& +\alpha_{3}\left[u \circ y\left(z^{h}+z^{m}\right)-c \circ y\left(z^{h}+z^{m}\right)\right]+\text { constant }
\end{aligned}
$$

where $z^{m}$ and $z^{h}$ depend on $i^{m}$ and $i^{h}$ through (12)-(13). As is standard in the literature, monetary policies affect the welfare only through the social value of production in the DM. We first present the following result without a proof.

Lemma 3 The first best is achieved at $i^{m}=0$ and $i^{h}=0$. And $\partial \Omega\left(i^{m}, 0\right) / \partial i^{m}<0$ and $\partial \Omega\left(0, i^{h}\right) / \partial i^{h}<0$.

If the central bank can control both $i^{h}$ and $i^{m}$, it can achieve the first best by implementing the Friedman rule for both monies. If the central bank can control only $i^{m}$, an immediate consequence of Lemma 3 is that the optimal $i^{m}$ is 0 if $i^{h}=0$. However, if $i^{h}>0$, the optimal $i^{m}$ may be different from the Friedman rule.

Proposition 4 If $\alpha_{2}, \alpha_{3}>0, \alpha_{2} \lambda(0)>i^{h}>0$, then the optimal central bank policy $i_{*}^{m}$ satisfies

1. If $\alpha_{1}>0$ is sufficiently small, then $0<i_{*}^{m}<\bar{\imath}^{m}$.

2. If $\alpha_{1}=0$ and $i^{h}$ is not too big, then $i_{*}^{m} \geq \bar{\imath}^{m}$ and fiat money is not valued.

\section{Proof. See Appendix D.}

Intuitively, if $\alpha_{1}=0$ and $i^{m}=0$, consumption is efficient in type 1 and 3 transactions under the Kalai bargaining. But it is below the efficient level in type 2 transactions because $i^{h}>0$. An increase in $i^{m}$ from 0 results in a second-order welfare loss by reducing consumption in type 1 and 3 transactions. But it leads to

\footnotetext{
${ }^{8}$ We trade type 2 transactions to be legitimate transactions instead of crimes. If these transactions are criminal activities, the optimal policy of the central bank is always the Friedman rule regardless of the e-money issuer's policy.
} 
a first-order gain by raising consumption in type 2 transactions. As a result, this leads to a total welfare gain. By continuity, the same holds if $\alpha_{1}$ is sufficiently small. Notice that the key to this argument is that at $i^{m}=0$, consumption is efficient in type 1 and 3 transactions. Therefore, Proposition 4 holds under other trading mechanisms that share this property, such as competitive pricing and the strategic game analyzed in Zhu (2018).

If $\alpha_{1}>0$, it is never optimal to $i^{m} \geq \bar{\imath}^{m}$ because households would like to consume in type 1 transactions. But if $\alpha_{1}=0$, it is optimal to maximize the value of e-money by driving fiat money out of circulation.

We now illustrate how $i^{h}$ affects the $i_{*}^{m}$ using numerical examples. Figure 2 shows welfare as a function of $i^{m}$ under different values of $i^{h}$. In these examples, $\alpha_{1}>0 .{ }^{9}$ If $i^{h}=0$, welfare is monotonically decreasing in $i^{m}$ and has a unique peak at $i^{m}=0$. Therefore, the Friedman rule $\left(i_{*}^{m}=0\right)$ is the optimal policy. If $i^{h}$ increases to 0.02 , welfare is non-monotone in $i^{m}$. If $i^{m}$ is small, buyers are unconstrained in type 3 transactions. An increase in $i^{m}$ reduces consumption in type 1 transactions but does not affect consumption in type 2 and 3 transactions. Therefore, higher $i^{m}$ leads to lower welfare. If $i^{m}$ is sufficiently large, liquidity becomes scarce in type 3 transactions. An increase in $i^{m}$ makes households more constrained in type 3 transactions. This raises the value of e-money because it can also be used in type 3 transactions. As a result, buyers can consume more in type 2 transactions. If the gains in type 2 transactions dominate the losses in type 1 and 3 transactions, the total welfare increases with $i^{m}$. Therefore, the welfare function has two peaks: one at $i^{m}=0$ and one at $i^{m}>0$. Because $i^{h}$ is not very high, the peak at $i^{m}=0$ is higher and $i_{*}^{m}=0$. If $i^{h}$ further increases, the peak at $i^{m}>0$ becomes higher and $i_{*}^{m}>0$. Lastly, if $i^{h}$ is sufficiently high, as shown in Figure 2(d), the Friedman rule is optimal. In this case, e-money is not valued if $i^{m}$ is not sufficiently high. As a

\footnotetext{
${ }^{9}$ All the parameters are shown in Table 2 .
} 


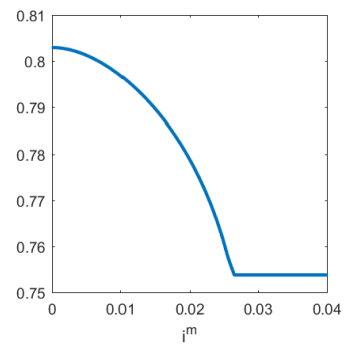

(a) $i^{h}=0$

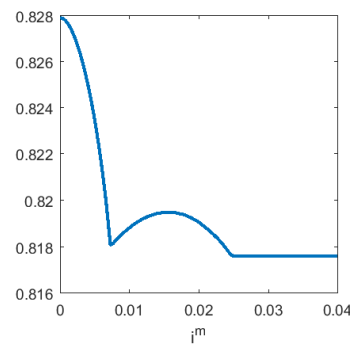

(b) $i^{h}=0.02$

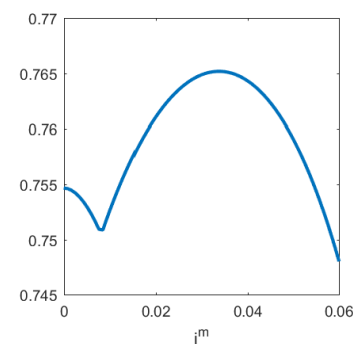

(c) $i^{h}=0.04$

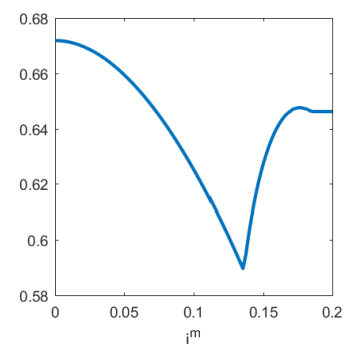

(d) $i^{h}=0.22$

Figure 2: Example 2: Welfare as a Function of $i^{m}$

result, welfare decreases with $i^{m}$ until a point at which e-money is valued. Then both monies are valued and households can consume in type 2 transactions. Higher $i^{m}$ increases welfare through the mechanism described above. This leads to the local maximium with $i^{m}>0$. Because holding e-money is very costly, the Friedman rule yields higher welfare and e-money is then not valued.

It may be natural to think the e-money issuer may not set $i^{h}=0$ even if they are benevolent. To implement $i^{h}=0$, the e-money issuer needs to buy back emoney in the CM, which results in a loss. The e-money issuer may not do so if he cannot finance himself through taxes or donations, which is likely the case for a private issuer. In this case, the central bank's optimal policy may deviate from the Friedman rule.

\section{Policy Game: Simultaneous Move}

Now suppose the private issuer is a firm owned by households. It chooses $i^{h}$ to maximize its seigniorage income and transfers all the profit in lump sum back to households. We consider a two-stage policy-setting game. In the first stage, the central bank and the e-money issuer simultaneously set their long-run interest rates. In the second stage, the economy figures out the steady state equilibrium given the 
policy choices. ${ }^{10}$

Let the per-period seigniorage income of the e-money issuer be

$$
\Pi\left(i^{m}, i^{h}\right)=\left[\beta\left(i^{h}+1\right)-1\right] z^{h} /\left[\beta\left(i^{h}+1\right)\right]
$$

where $z^{h}$ depends on both $i^{m}$ and $i^{h}$ through (12)-(13). ${ }^{11}$ If $\beta\left(i^{h}+1\right)-1>0$, the e-money authority is selling e-money in the CM and earns a profit. ${ }^{12}$ The e-money issuer maximizes $\Pi\left(i^{m}, i^{h}\right)$ by setting $i^{h}$ taking $i^{m}$ as given while the central bank sets $i^{m}$ to maximize $\Omega\left(i^{m}, i^{h}\right)$ taking $i^{h}$ as given. We focus on the pure strategy Nash equilibrium because it is easy to interpret.

It is difficult to establish a general existence result of a pure strategy equilibrium. ${ }^{13}$ In principle, $\Pi\left(i^{m}, i^{h}\right)$ may be non-concave or even non-monotone in $i^{h}$. The same is true for $\Omega\left(i^{m}, i^{h}\right)$ as a function in $i^{m}$. Moreover, this game may not be super modular. In fact, we show in numerical examples that the best response functions of the central bank and the e-money issuers may both have discontinuities, which may potentially lead to non-existence of a pure strategy equilibrium. This complication arises because the demand for monies emerges endogenously from the liquidity premium. Its second derivative determines the properties of $\Pi\left(i^{m}, i^{h}\right)$ and $\Omega\left(i^{m}, i^{h}\right)$, which depend on the third-order derivatives of the utility and cost functions. However, in all of the numerical examples considered below, the pure strategy equilibrium exists. And in some cases, we can derive easy-to-check conditions for the

\footnotetext{
${ }^{10}$ In other words, we restrict the action space to be policies that have constant long-run money growth rates. We do not consider time-varying policies. This policy-setting game is related to Zhang (2014) and Geromichalos and Herrenbrueck (2016). The former considers a game where two central banks compete to set policies to maximize welfare of their own citizens. The latter considers an optimal asset issuance problem with two competing asset issuers.

${ }^{11} \mathrm{An}$ alternative formulation is that at the first stage, the e-money issuer initially issues e-money and then chooses $i^{h}$ to maximize its total revenue, which includes both the revenue from initial issuance and the total seigniorage income, i.e., $\Pi^{h}\left(i^{m}, i^{h}\right)=z^{h}+$ $\frac{\beta}{1-\beta}\left[\beta\left(i^{h}+1\right)-1\right] z^{h} /\left[\beta\left(i^{h}+1\right)\right]$. The results are similar qualitatively.

${ }^{12}$ Note that the e-money issuer need never incur a loss, since it can always break even by setting $i^{h}=1 / \beta-1$.

${ }^{13}$ If we allow for mixed strategy equilibria, it is easy to show that a Nash equilibrium exists by Glicksberg's theorem.
} 
existence of a pure strategy equilibrium. For more discussions, pleaes see Appendix E. In the rest of this section, we focus on the properties of the pure strategy equilibrium given that it exists. Let $i_{*}^{m}$ and $i_{*}^{h}$ be the equilibrium outcome. We first provide conditions under which the Friedman rule cannot be an equilibrium outcome.

Proposition 5 If $\alpha_{2} \lambda(0)>1 / \beta-1$, then $i_{*}^{h}>1 / \beta-1$. If in addition, $\alpha_{3}>0$ and $\alpha_{1}$ is sufficiently small, $i_{*}^{m}>0$.

Proof. Given any $i^{m}$, if $i^{h} \leq 1 / \beta-1$ leads to non-positive seigniorage income, while $\alpha_{2} \lambda(0)>i^{h}>1 / \beta-1$ yields strictly positive seniorage income. This proves the first claim. For the second claim, just notice that by proposition $4, i_{*}^{m}>0$ because it maximizes welfare under $i_{*}^{h}>1 / \beta-1$.

We now use some numerical examples to illustrate the equilibrium. We start with an analysis of the e-money issuer's best response.

Figure 3 shows the per-period seigniorage income of the e-money issuer as a function of $i^{h}$ under different values of $i^{m}$. Parameters are shown in Table 2. If $i^{m}=0$, buyers are not constrained in type 3 transactions. Then $\Pi^{h}\left(i^{m}, i^{h}\right)$ reduces to $\left[\beta\left(i^{h}+1\right)-1\right] \lambda^{-1}\left(i^{h} / \alpha_{2}\right) /\left[\beta\left(i^{h}+1\right)\right]$. It has a unique peak at around $i^{h}=$ 0.038. This is the best response of the e-money issuer to $i^{m}=0$. Intuitively, the effect of $i^{h}$ has two effects: it increases the amount of new e-money issued each period and decreases the value of e-money. The former effect raises $\Pi^{h}\left(i^{m}, i^{h}\right)$ and the latter reduces it. When $i^{h}$ increases from 0 , the former effect dominates and hence the income increases. If $i^{h}$ is too large, the latter dominates and $\Pi^{h}\left(i^{m}, i^{h}\right)$ decreases.

If $i^{m}=0.008, \Pi^{h}\left(i^{m}, i^{h}\right)$ overlaps with the one under $i^{m}=0$ until $i^{h}$ reaches around 0.04 , where a kink occurs. To the left of the kink, buyers in type 3 transactions are unconstrained and the seigniorage income is the same as in the case of $i^{m}=0$. To the right of the kink, buyers are constrained in type 3 transactions. 
The kink occurs in the decreasing region of the seigniorage income function under $i^{m}=0$. The optimal $i^{h}$ under $i^{m}=0$ remains a local maximizer at $i^{m}=0.008$. Just to the right of the kink, type 3 transactions contribute to the liquidity premium. As a result, the adverse effect of $i^{m}$ on the value of e-money is alleviated. Consequently, the seigniorage income starts to increase again. It eventually decreases as $i^{h}$ further increases. This leads to the second local maximizer at which buyers are constrained in type 3 transactions. Now the second local maximizer yields a lower seigniorage income compared to the first local maximizer. The best response remains the same as for $i^{m}=0$.

If $i^{m}$ further increases to 0.0085 , the kink happens earlier because $i^{m}$ reduces the value of fiat money, making buyers more constrained in type 3 transactions. The local maximum to the right of the kink becomes larger than the one to the left of the kink. The best response of the e-money issuer changes to the local optimal where buyers are constrained in type 3 transactions. Notice there exists a value of $i^{m}$ at which both local maximums are equal. This leads to two best responses under that $i^{m}$. If $i^{m}$ increases to 0.01 , then the kink occurs before the first local maximizer is reached. And now the seigniorage income function has a unique local maximizer, which is also the global maximizer.

This property of the seigniorage income translates to the best response function shown in Figure 4(a). If $i^{m}$ is sufficiently small, the local maximizer to the left of the kink in Figure 3 yields the highest income. The best response stays unchanged for all such $i^{m}$. As $i^{m}$ increases, the best response jumps because the local maximum to the right of the kink in Figure 3 yields higher income, causing a discountinuity in the response function. At the jumping point, the two local maximizers are both the best responses. As $i^{m}$ further increases, fiat money and e-money co-exist until the first kink on the best response function, shown in Figure 4(a), occurs. To the right of that kink, $i^{m}$ is sufficiently high and it is optimal for the e-money issuer to drive fiat 




Figure 3: Seigniorage Income as a Function of $i^{h}$

money out of market. In this region, the e-money issuer still faces competition from the fiat money and cannot act as a monopolist. If he chooses a policy ignoring fiat money, fiat money will be valued, leading to a lower seigniorage income. If $i^{m}$ further increases, the second kink in Figure 4(a) occurs. Then $i^{m}$ is so high that even if the e-money issuer acts as if he or she is the monopolist, fiat money cannot be valued. Then her best response does not depend on $i^{m}$ and the best response function is vertical. It is worth noting that the best response function of the e-money issuer is not necessarily increasing in $i^{m}$. In fact, in the numerical examples, we find it to be decreasing just to the left of the first kink.

Similarly, we can obtain the best response of the central bank as shown in Figure 4(b). This best response function has two jumps. The jump at the lower $i^{h}$ happens because the local maximum at $i^{m}>0$ becomes the global maximum illustrated in Figure 2. The jump at the higher $i^{h}$ happens because it is optimal for the central bank to drive e-money out of circulation if $i^{h}$ is sufficiently large.

We now turn to the equilibrium. Any intersection of the two best response 
functions is a pure strategy equilibrium. In Example 3, there is only one intersection with $i_{*}^{h}=0.065$ and $i_{*}^{m}=0.056$. The equilibrium yields lower welfare compared to the first best, which requires $i^{m}=0$ and $i^{h}=0$.

Now focus on the equilibrium in Example 4, which is plotted in the second column. The best response functions have two intersections. This leads to two equilibria: one with $i_{*}^{h}=0.038$ and $i_{*}^{m}=0$ and one with $i_{*}^{h}=0.062$ and $i_{*}^{m}=0.053$. The second equilibrium leads to lower welfare compared to the first. The possibility of multiple equilibria highlights the monetary policy coordination issue. ${ }^{14}$

It is worth noting that the difference between Example 3 and Example 4 is that $\alpha_{1}$ is smaller in Example 3. As predicted by Proposition 5, any Nash equilibrium has $i^{m}>0$ if $\alpha_{1}$ is sufficiently small. This has important implications on how declining usage of the fiat money can have a negative impact on the economy. To see this, suppose the central bank is able to pick the good equilibrium. When usage of the fiat money is high, i.e., $\alpha_{1}$ is high, there are multiple equilibria and the economy operates at the low inflation, high welfare equilibrium. But if the fiat money usage goes down as $\alpha_{1}$ drops below a threshold, the good equilibrium ceases to exist and the economy jumps to the high inflation equilibrium, resulting in a discrete drop in welfare and a discrete increase in inflation. Figure 6 illustrates this. It is contructed under the parameters of Example 4 except that $\alpha_{1}+\alpha_{2}=0.12$. As $\alpha_{1}$ decreases, $\alpha_{2}$ increases. When $\alpha_{1}$ drops below around 0.05, the good equilibrium disappears and welfare drops dramatically, as shown in Figure 6(a). Interestingly, as $\alpha_{1}$ further decreases, the welfare increases. This captures the network externality: it is beneficial if all agents use the same money. However, the gain from the network externality cannot fully compensate the loss due to the e-money issuer's increasing monopoly power. The total welfare is lower at $\alpha_{1}=0$ compared to at $\alpha_{1}=0.1$. Moreover, inflation at

\footnotetext{
${ }^{14}$ In general, we cannot establish existence of pure strategy equilibrium because the best response functions are both discontinuous.
} 


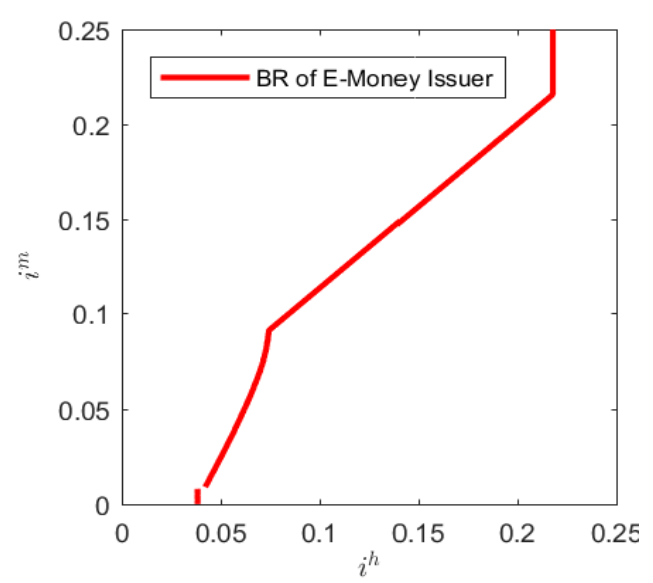

(a) Example 3

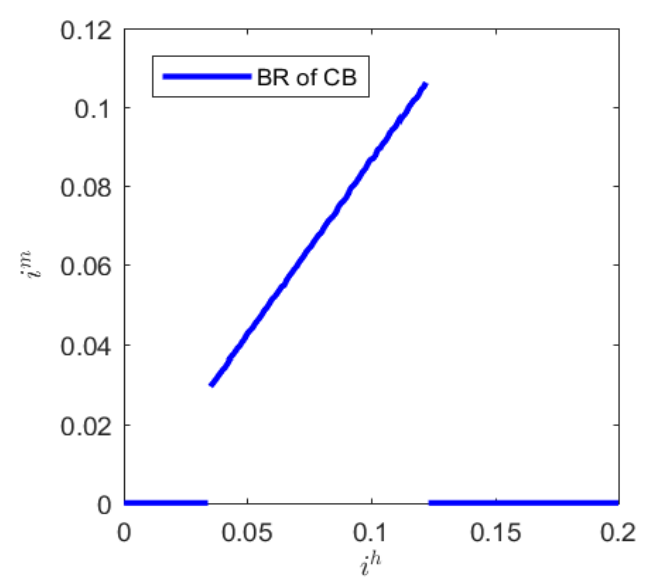

(b) Example 3

Figure 4: Policy Game: Best Response Functions

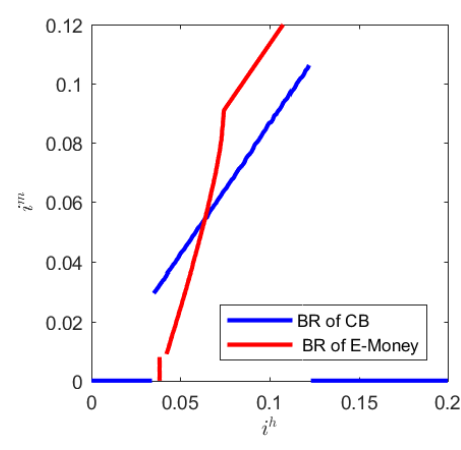

(a) Example 3

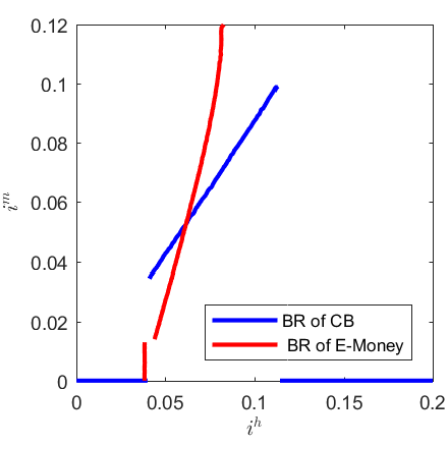

(b) Example 4

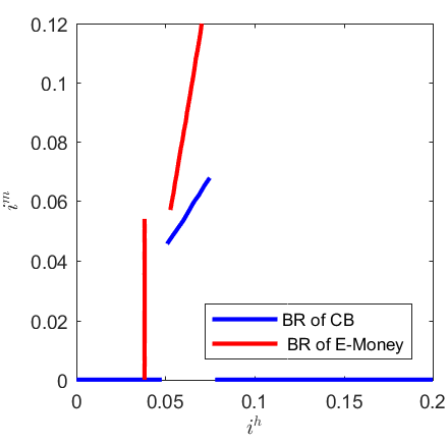

(c) Example 5

Figure 5: Policy Game: Equilibrium

the equilibrium jumps up as shown in Figure 6(b). This is because higher $\alpha_{2}$ enables the e-money issuer to run higher inflation. The central bank's optimal response makes inflation even higher because it is beneficial to encourage e-money usage.

\section{Policy Game: Sequential Move}

Now, we consider a sequential game in which the central bank first sets its monetary policy and then the e-money issuer follows. This game is more suitable in cases where the central bank can commit to not responding to the e-money policy. 


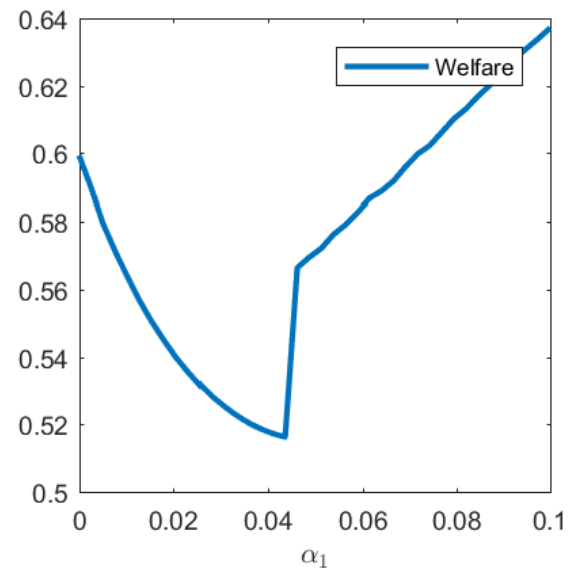

(a) Welfare

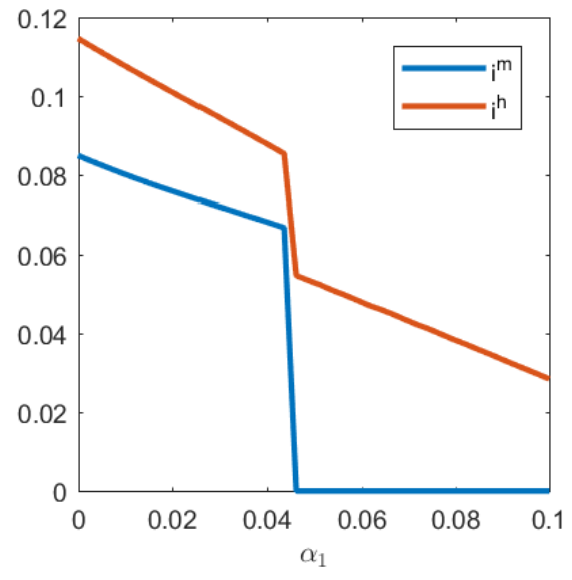

(b) Equilibrium Policies

Figure 6: Effects of Declining Fiat Money Usage

\begin{tabular}{c|ccccccccc}
\hline \hline Ex & $\sigma$ & $\varepsilon$ & $\beta$ & $\theta$ & $\alpha_{1}$ & $\alpha_{2}$ & $\alpha_{3}$ & $i^{m}$ & $i^{h}$ \\
\hline \hline 1 & 1.76 & 0.05 & 0.98 & 0.5 & 0.01 & 0.01 & 0.4 & 0.041 & 0.041 \\
2 & 0.90 & 0.05 & 0.98 & 0.50 & 0.01 & 0.1 & 0.40 & $N / A$ & \\
3 & 0.90 & 0.05 & 0.98 & 0.50 & 0.03 & 0.06 & 0.40 & $N / A$ & $N / A$ \\
4 & 0.90 & 0.05 & 0.98 & 0.50 & 0.055 & 0.06 & 0.40 & $N / A$ & $N / A$ \\
5 & 0.90 & 0.05 & 0.98 & 0.50 & 0.3 & 0.06 & 0.40 & $N / A$ & $N / A$ \\
\hline \hline
\end{tabular}

Table 2: Parameters for Numerical Experiments $u(y)=\frac{(y+\varepsilon)^{1-\sigma}-\varepsilon^{1-\sigma}}{1-\sigma}, c(y)=y$. 


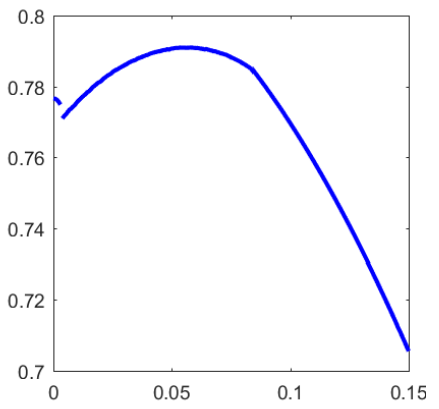

(a) Example 2

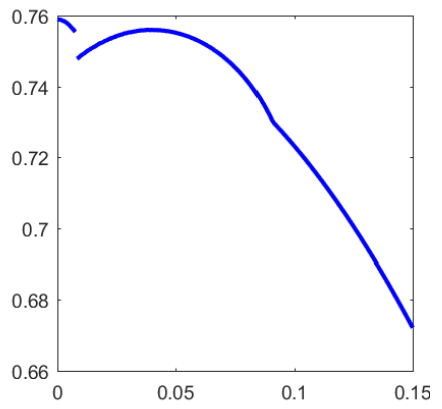

(b) Example 3

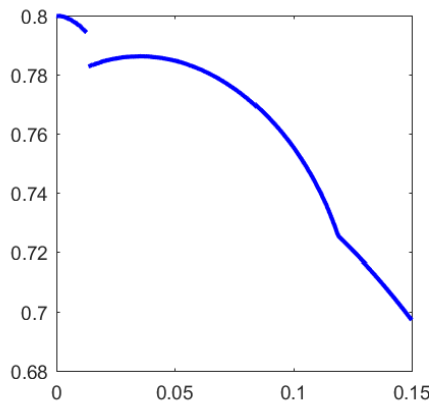

(c) Example 4

Figure 7: Welfare as a Function of $i^{m}$ with Sequential Move

In this game, the central bank takes the e-money issuer's best response as given and tries to set a policy that maximizes the total welfare. As shown in Figure 4(a), the best response of the private issuer is increasing in $i^{m}$ but can potentially have jumps. At the jump, two different values of $i^{h}$ yield the same seigniorage income for the e-money issuer. If we assume that the e-money issuer always picks the smallest $i^{h}$ if there are maximizers of the seigniorage income, the total welfare function is upper semi-continuous in $i^{m}$. Consequently, there exists at least one solution to the central bank's problem. In addition, we can obtain an analogous result of Proposition 5.

Proposition 6 If $\alpha_{1}$ is sufficiently small and $\alpha_{3}>0$, the optimal policy $i_{*}^{m}>0$ in the sequential move game.

Proof. Proof omitted because it is similar to that of Proposition 5.

Figure 7 shows the total welfare as a function of $i^{m}$ in Examples $2-4$ in the sequential move game. In principle, it can have four regions separated by kinks or discontinuities, which correspond to the four regions of the e-money issuer's best response function. In Figure 7, we show only the first three regions. In the first region, $i^{m}$ is sufficiently small and welfare is strictly decreasing. As $i^{m}$ increases to a certain level, the e-money issuer's best response jumps up. Consequently, welfare drops discontinuously, which starts the second region. In this region, a higher $i^{m}$ 
first increases welfare because gains from type 2 transactions dominate and then decreases welfare because losses from type 1 and 3 transactions dominate. In the first two regions, e-money and fiat money co-exist. As $i^{m}$ further increases, a kink marks the start of the third region. In this region, the e-money issuer finds it optimal to drive out fiat money. If $i^{m}$ is higher, the e-money issuer can drive out fiat money at a higher $i^{h}$. Hence, a higher $i^{m}$ unambiguously decreases welfare. If $i^{m}$ further increases, another kink occurs and the fourth region starts. In this region, fiat money is not valued even if the e-money issuer acts as if it is the only money issuer in the economy. Then, welfare stays constant as $i^{m}$ increases.

Compared to the simultaneous move game, the outcome can be more efficient if the CB moves first. This is true under the parameters of example 3 and 4, as shown in Figures 7(b) and 7(c). In both cases, the equilibrium in the sequential game is $i^{m}=0$. In Example 3, the equilibrium of the sequential move game strictly dominates that of the simultaneous move game. In Example 4, the sequential move game picks out the more efficient equilibrium in the simultaneous move. However, if $\alpha_{1}$ is sufficiently small, as in Example 2, the optimal $i^{m}$ can still be positive. This is shown in Figure $7(\mathrm{a})$.

To sum up, in the sequential move game, the central bank has more ability to control inflation because it commits to not responding to the private issuer. This yields better outcome. But again, as the economy becomes cashless, it is optimal for the central bank to tolerate more inflation for higher welfare. If the central bank can issue its own e-money, which is designed to be a perfect substitute for the private e-money, it can achieve the first best by setting the Friedman rule for both monies. This would drive the private e-money out of circulation. 


\section{Extensions}

\subsection{Homogeneous Fixed Cost of Adoption}

Now we endogenize the adoption decisions of e-money. Suppose that type 3 entrepreneurs can accept fiat money at no cost and may accept e-money in the next LW market only if they pay a per-period cost $\kappa$ in the current $\mathrm{AD}$ market.

Let $\tau$ be the acceptance rate of e-money in type 3 transactions. Given $\tau$, the equilibrium is determined by

$$
\begin{aligned}
i^{m} & =\left[\alpha_{1}+\alpha_{3}(1-\tau)\right] \lambda\left(z^{m}\right)+\alpha_{3} \tau \lambda\left(z^{m}+z^{h}\right) \\
i^{h} & =\alpha_{2} \lambda\left(z^{h}\right)+\alpha_{3} \tau \lambda\left(z^{m}+z^{h}\right) .
\end{aligned}
$$

These two equations implicitly define $z^{m}=Z^{m}(\tau)$ and $z^{h}=Z^{h}(\tau)$. If a type 3 entrepreneur chooses to accept e-money, he can sell more upon meeting a buyer. This benefit is

$$
\begin{aligned}
& \Sigma(\tau)=\beta \alpha_{s}\left\{P\left[Z^{m}(\tau)+Z^{h}(\tau)\right]-c \circ Y\left[Z^{m}(\tau)+Z^{h}(\tau)\right]\right\} \\
& -\beta \alpha_{s}\left\{P\left[Z^{m}(\tau)\right]-c \circ Y\left[Z^{h}(\tau)\right]\right\} \text {. }
\end{aligned}
$$

Let $\sigma$ be the best response function for the type 3 entrepreneur. Then we have

$$
\sigma(\tau)=\left\{\begin{array}{cl}
1 & \text { if } \kappa<\Sigma(\tau) \\
(0,1) & \text { if } \kappa=\Sigma(\tau) \\
0 & \text { if } \kappa>\Sigma(\tau)
\end{array} .\right.
$$

Then the equilibrium is characterized by (14)-(15) and $\sigma(\tau)=\tau$.

To analyze the equilibrium, we first derive properties of $\Sigma(\tau)$.

Lemma 7 (1) $\Sigma(\tau)$ is weakly increasing in $\tau$. (2) $\Sigma(\tau)$ is weakly increasing in $i^{m}$ for a given $\tau$. (3) $\Sigma(\tau)$ is weakly increasing in $\alpha_{2}$ for a given $\tau$.

Proof. If $\tau$ increases, $Z^{h}(\tau)$ increases and $Z^{m}(\tau)$ decreases. As a result, $P\left[Z^{m}(\tau)+Z^{h}(\tau)\right]-$ $c \circ Y\left[Z^{m}(\tau)+Z^{h}(\tau)\right]$ increases weakly and $P\left[Z^{m}(\tau)\right]-c \circ Y\left[Z^{h}(\tau)\right]$ decreases. This proves (1). The rest can be shown in the same way. 


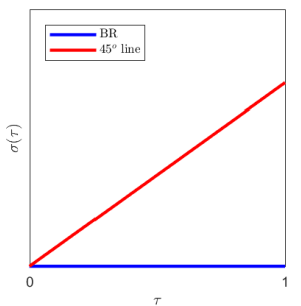

(a) High $\kappa$

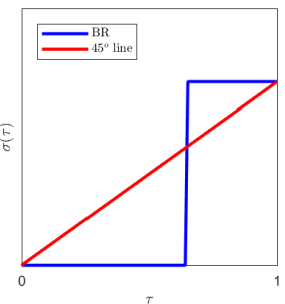

(b) Intermediate $\kappa$

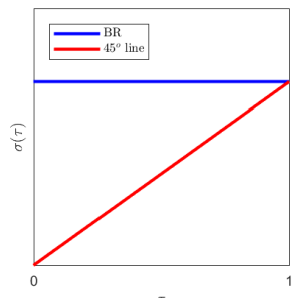

(c) Low $\kappa$

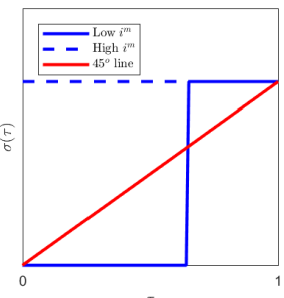

(d) Different $i^{m}$

Figure 8: Best Response

Intuitively, an increase in $\tau$, or $i^{m}$, or $\alpha_{2}$ makes e-money more attractive and buyers hold more of it. As a result, the benefit from accepting e-money increases.

Proposition 8 The steady state has three possibilities. (1) If $\Sigma(0)>\kappa$, e-money is accepted in all type 3 transactions. (2) If $\Sigma(1)<\kappa$, e-money is not accepted in type 3 transactions. (3) If $\Sigma(0)<\kappa<\Sigma(1)$, there exist three equilibria. E-money may be accepted in all type 3 transactions, or not in any type 3 transactions, or in a fraction $\tau \in(0,1)$ of type 3 transactions where $\kappa=\Sigma(\tau)$.

Proof. By Lemma 7, $\Sigma(\tau)$ is weakly increasing. Hence, if $\Sigma(0)>\kappa, \Sigma(\tau)>\kappa$ for any $\tau$. Hence, the only equilibrium is $\tau=1$. Similarly, $\tau=0$ if $\Sigma(1)<\kappa$. If $\Sigma(0)<\kappa<\Sigma(1), \sigma(0)=0$ and hence $\tau=0$ is an equilibrium. Similarly, $\tau=1$ is another equilibrium. In addition, by continuity of $\Sigma(\tau)$, there exists a $\tau \in(0,1)$ such that $\kappa=\Sigma(\tau)$, which is the third equilibrium.

If $\kappa$ is sufficiently high, the e-money is used only as a niche money in the equilibrium. If $\kappa$ is sufficiently low, e-money is accepted in all trades. For intermediate $\kappa$, there exist equilibria with partial adoption, full adoption and no adoption. It is worth noting that if $i^{m}=0, \Sigma(\tau)=0$ for any $\tau$. This is because buyers are not constrained in type 3 transactions with only fiat money. Therefore, e-money is used only as a niche money for any $\kappa$. However, if $i^{m}>0, \Sigma(0)>0$. Then, type 3 entrepreneurs will accept e-money if $\kappa$ is sufficiently low. 
Figure 8 plots $\sigma(\tau)$ and the $45^{\circ}$ line. Any intersection between them constitutes an equilibrium. Figures 8(a)-8(c) are for different values of $\kappa$. If $\kappa$ is high, $\sigma(\tau)$ intersects the $45^{\circ}$ line only at the origin. Hence, the only possible equilibrium is $\tau=0$. If $\kappa$ is intermediate, $\sigma(\tau)$ cuts the $45^{\circ}$ line at $\tau=0, \tau=1$ and some $\tau \in(0,1)$. As a result, there are three equilibria: (1) all type 3 entrepreneurs do not accept e-money; (2) all of them accept e-money; and (3) some accept and some do not. Notice that $\tau=0$ and $\tau=1$ are two stable equilibria. The one at $\tau \in(0,1)$ is unstable. An increase in $\tau$ leads people to accept with probability 1 and a decrease leads to no acceptance. Lastly, if $\kappa$ is sufficiently low, the only equilibrium is at $\tau=1$

This analysis illustrates the discontinuities that can arise in adoption of e-money. E-money can serve as niche money that is used only in type 2 transactions. As $\kappa$ decreases, e-money may still continue to be niche money, i.e., agents coordinate on the equilibrium with $\tau=0$. But if $\kappa$ becomes sufficiently large, the equilibrium with $\tau=0$ disappears and suddenly, the economy switches to the equilibrium with $\tau=1$. Inappropriate monetary policy by the central bank can expedite this process. Figure 8(d) illustrates this. If $i^{m}$ is low, $\sigma(\tau)$ is depicted by the blue solid line. There exists equilibria with $\tau=0$ and $\tau \in(0,1)$. But if $i^{m}$ is high, $\sigma(\tau)$ changes to the dashed line. Then the only equilibrium is $\tau=1$. Intuitively, a higher $i^{m}$ makes buyers more constrained by using only fiat money and raises the benefits of using e-money. As a result, type 3 entrepreneurs are more willing to accept e-money.

Our previous analysis on optimal monetary policy remains valid here. To see this, notice that the previous results are under $\kappa=0$. By continuity, the same conclusions hold under any sufficiently small $\kappa$. Figure 9 illustrates that $i_{*}^{m}$ can be positive given an exogenous $i^{h}$. If $i^{m}$ is low, the e-money is not accepted by type 3 entrepreneurs. An increase in $i^{m}$ reduces welfare. If $i^{m}$ is sufficiently high, e-money is accepted by 


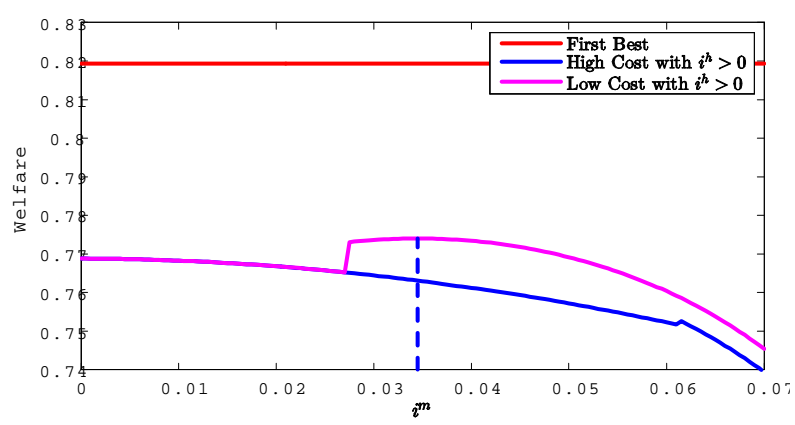

Figure 9: Welfare as a Function of $i^{m}$ with $\kappa>0$

all type 3 entrepreneurs. ${ }^{15}$ Then buyers can consume more. This benefit outweighs the fixed cost to accept e-money as long as $\kappa$ is not too high. Therefore, welfare jumps up. Upon acceptance of e-money by type 3 entrepreneurs, e-money starts to be a substitute for fiat money. Then the effect of $i^{m}$ on e-money, which is described in previous sections, becomes active. Higher $i^{m}$ can raise welfare and $i_{*}^{m}$ can be positive. This happens if $\kappa$ is low, as shown by the magenta curve.

\subsection{Heterogeneous Fixed Cost of Adoption}

In the homogenous cost model, the mixed strategy equilibrium is unstable: in it, the adoption rate increases with adoption cost. When there is heterogeneity in the cost of adoption, there can be stable mixed-strategy equilibrium. For example, assume that $\kappa$ has distribution $F_{\kappa}(\cdot)$ with a density supported on $[\underline{\kappa}, \bar{\kappa}]$. This captures that the sellers may have different costs of adopting e-money. Again, let $\tau$ be the proportion of sellers in type 3 transactions who accept e-money. Then, given $\tilde{\tau}, \tilde{z}^{m}$ and $\tilde{z}^{h}$ solve

$$
\begin{aligned}
i^{m} & =\left[\alpha_{1}+\alpha_{3}(1-\tilde{\tau})\right] \lambda\left(\tilde{z}^{m}\right)+\alpha_{3} \tau \lambda\left(\tilde{z}^{m}+\tilde{z}^{h}\right), \\
i^{h} & =\alpha_{2} \lambda\left(\tilde{z}^{h}\right)+\alpha_{3} \tau \lambda\left(\tilde{z}^{m}+\tilde{z}^{h}\right) .
\end{aligned}
$$

\footnotetext{
${ }^{15}$ We pick the equilibrium with $\tau=0$ as long as it exists. If it does not exist, the only equilibrium is $\tau=1$.
} 
The seller accepts e-money if his surplus of accepting is higher than his own cost, i.e.,

$$
\sigma(\kappa, \tau)=\left\{\begin{array}{ll}
1 & \text { if } \kappa<\Sigma(\tilde{\tau}) \\
0 & \text { if } \kappa \geq \Sigma(\tilde{\tau})
\end{array} .\right.
$$

Any $\tau$ that satisfies that $F_{\kappa}(\Sigma(\tau))=\tau$ is an equilibrium.

There are several cases:

(1) $\bar{\kappa}<\Sigma(0)$. This case is plotted in Figure 10(a). The $\mathrm{x}$-axis is $\tau$ and the $y$-axis is $\Sigma(\tau)$ or $\kappa$. The blue solid line is $\Sigma(\tau)$ and the red dashed line is the quantile function of $\kappa$, i.e., $F_{\kappa}^{-1}$. Any intersection of these two curves is a solution to $F_{\kappa}(\Sigma(\tau))=\tau$ and hence is an equilibrium. In addition, $\tau=0$ is an equilibrium if the red curve lies above the blue curve at $\tau=0$. And $\tau=1$ is an equilibrium if the red curve lies below the blue curve. In this case, the only equilibrium is $\tau=1$, i.e., because the cost of adoption is so low that every type 3 seller accepts e-money.

(2) $\underline{\kappa}>\Sigma(1)$. This case is illustrated in Figure 10(b). Now the cost of adoption is so high that no one accepts e-money in type 3 transactions and e-money stays as niche money.

(3) The case with $\Sigma(1)>\bar{\kappa}>\underline{\kappa}>\Sigma(0)$ is depicted in Figure 10(c). Now $\tau=1$ and $\tau=0$ are both equilibria. The two curves also intersect once between $[0,1]$ and yield another equilibrium with $\tau \in(0,1)$. Due to the continuity of both curves, at least one such equilibrium exists. There might be more than one equilibria, depending on the shape of $F_{\kappa}$. One can see this from Figure 10(d). The red dashed curve intersects with the blue solid curve three times, leading to three equilibria with $\tau \in(0,1)$.

(4) If $\bar{\kappa}>\Sigma(1)>\underline{\kappa}>\Sigma(0)$, we must have $\tau \in(0,1)$ in the equilibrium. At least one such equilibrium exists, as illustrated in Figures 10(e) and 10(f).

(5) The case $\Sigma(1)>\bar{\kappa}>\Sigma(0)>\underline{\kappa}$ is illustrated in Figure 11(a) and Figure 11(b). In this case, $\tau=1$ is always an equilibrium. But there may not exist equilibria with $\tau \in(0,1)$ (Figure 11(a)), or more than one such equilibria (Figure 11(b)). 
(6) Similarly, if $\Sigma(1)>\bar{\kappa}>\Sigma(0)>\underline{\kappa}, \tau=1$ is an equilibrium. There may or may not exist other equilibria. The following proposition summarizes the above discussion.

Proposition 9 There exists at least one equilibrium. The number of equilibria depends on the shape of $F_{\kappa}$. If $\Sigma(1)>\underline{\kappa}$, there exists an equilibrium with $\tau>0$.

Next, we illustrate the effect of technological advances and the monetary policy of the central bank on adoption. Figure 12(a) illustrates the effect of technological progress that lowers the cost of adoption. The red dashed line depicts the quantile function of a high $F_{\kappa}$. It starts from 0 , meaning that there exist sellers with extremely low adoption cost and it intersects $\Sigma(\tau)$ only once. That is the only equilibrium in which both currencies are valued. As technology becomes better, the quantile function shifts to the magenta line, i.e., the cost distribution under the old technology first-order stochastically dominates that under the new technology. The adoption rate becomes higher and at the same time, two other equilibria appear. One is $\tau=1$ and the other is a second mixed equilibrium with a higher $\tau<1$. The equilibrium with the lower $\tau>0$ is a stable equilibrium. Another technological advance further lowers the cost to the black dot-dash curve. Then, the only equilibrium is $\tau=1$. Figure 12(b) illustrates the effect of higher inflation that drives the net surplus of adoption to the magenta line. The adoption rate of e-money is higher as the central bank runs a higher inflation.

\subsection{Stabilization Policy}

One often-asserted advantage of fiat money is that the central bank can stabilize the economy by using active monetary policy. E-money issuers may not have the ability to do so. It would be interesting to see how the stabilization policy affects the adoption of e-money. The benchmark model can be modified to answer this question. 


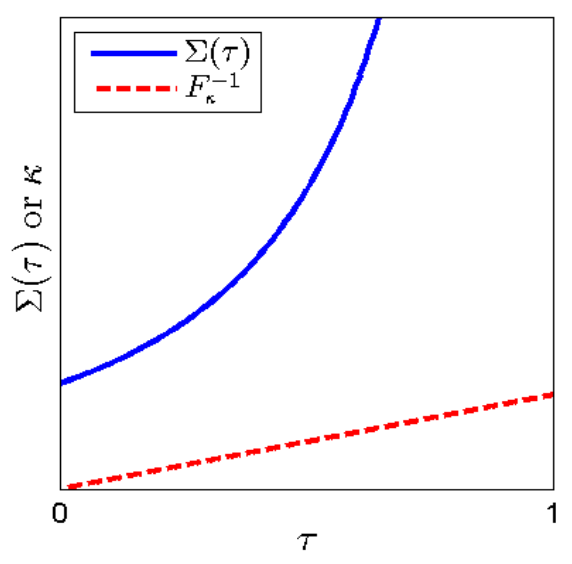

(a) Case 1

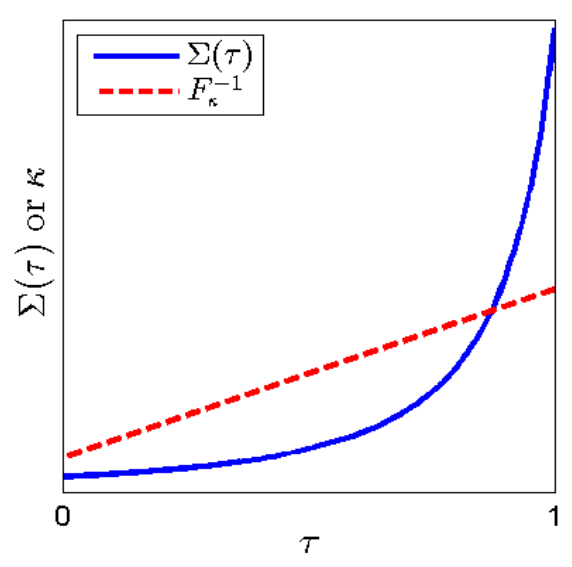

(c) Case $3 a$

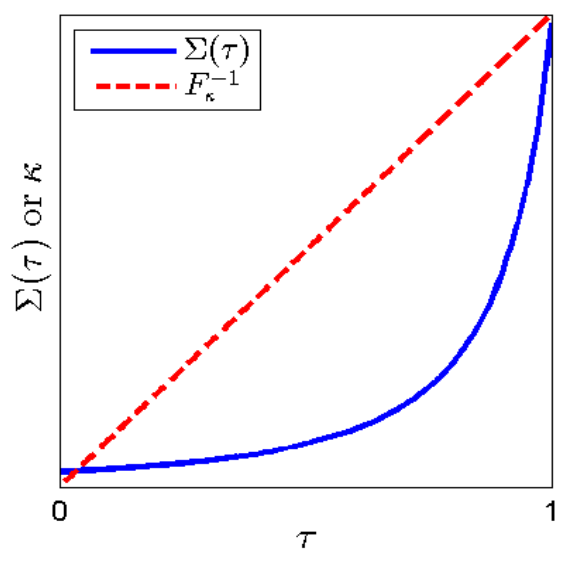

(e) Case $4 \mathrm{a}$

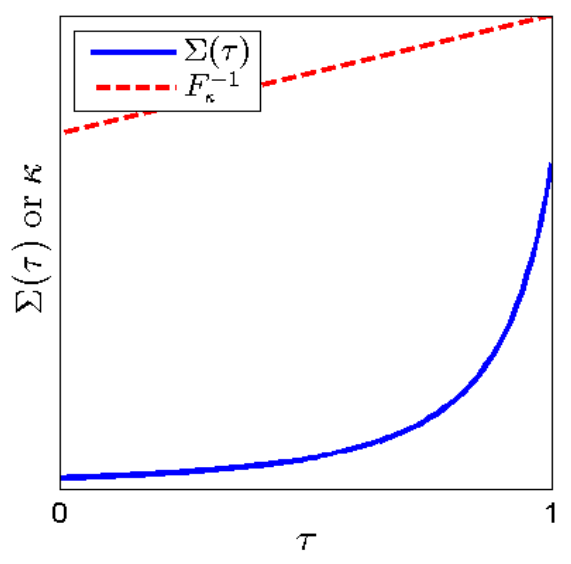

(b) Case 2

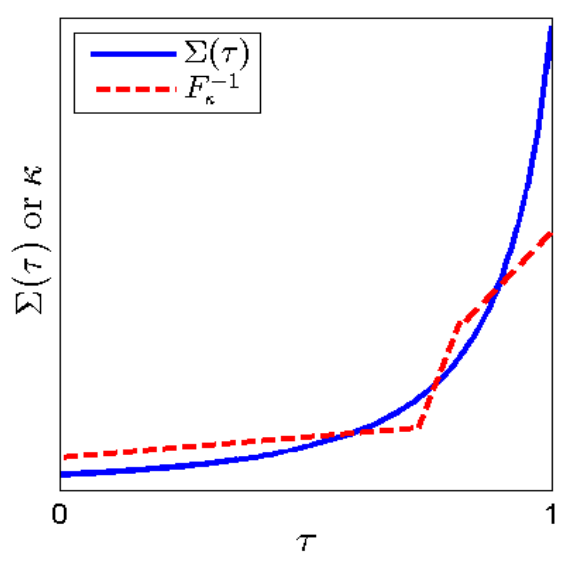

(d) Case 3b

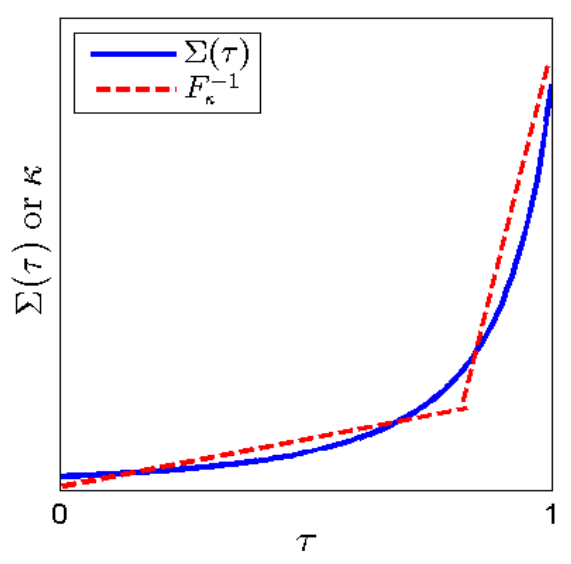

(f) Case 4b

Figure 10: Equilibrium: Case 1 to Case 4 


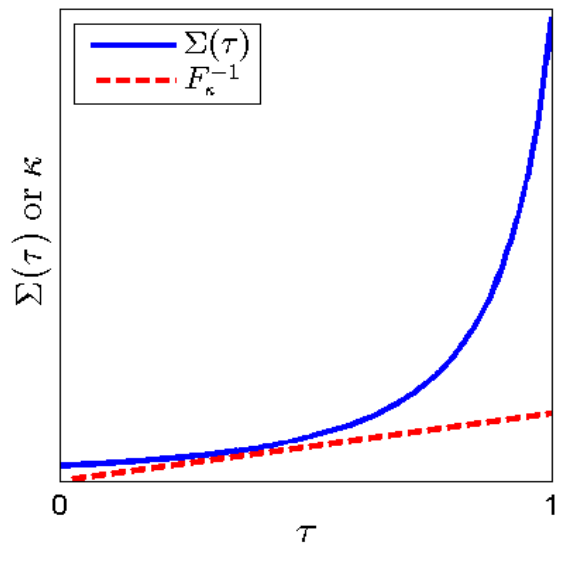

(a) Case 5a

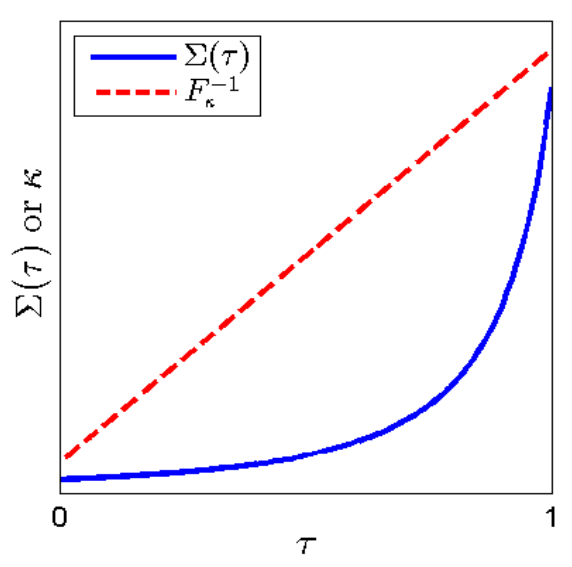

(c) Case 6a

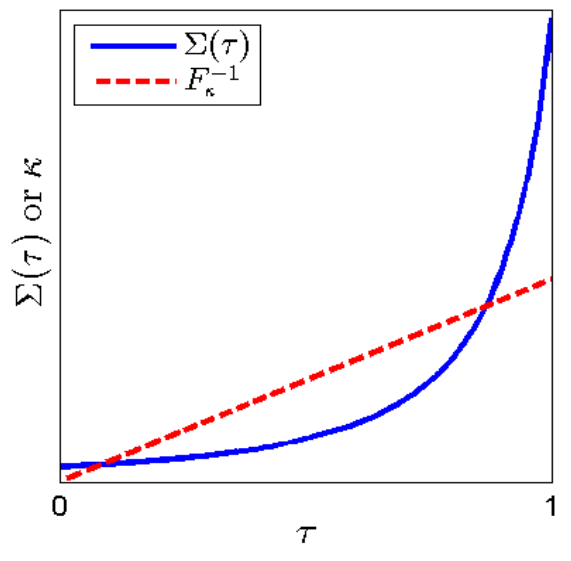

(b) Case 5b

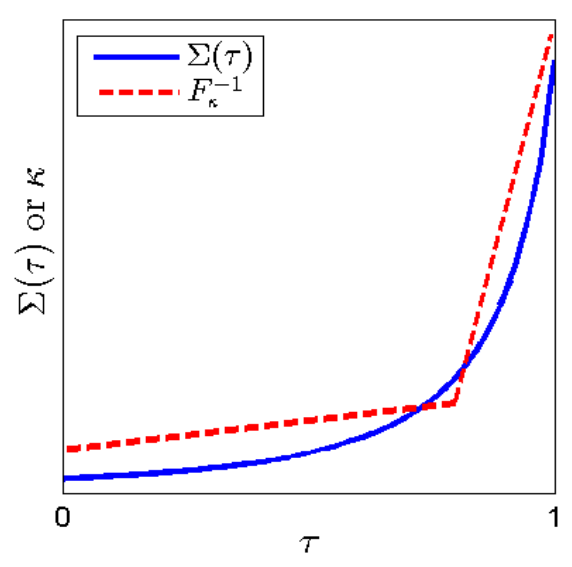

(d) Case 6b

Figure 11: Equilibrium: Case 5 to Case 6 


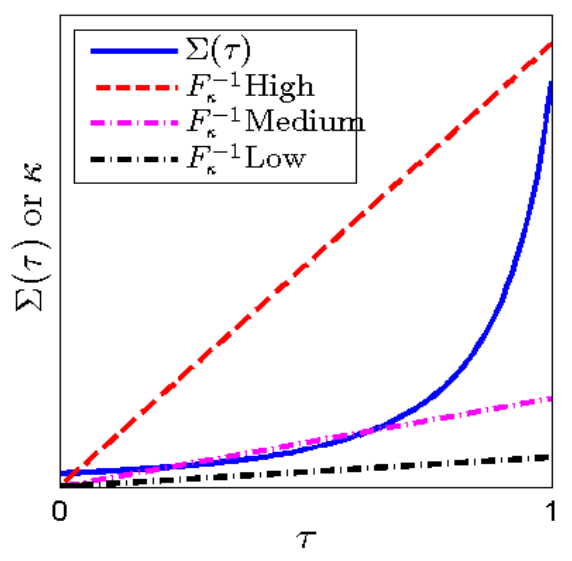

(a) Technology Change

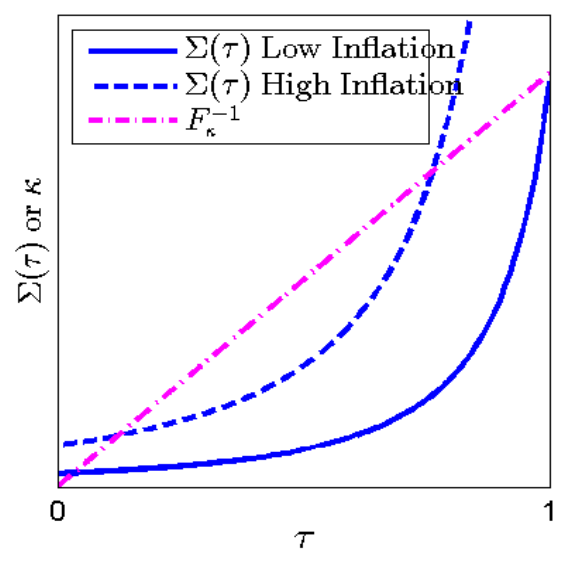

(b) Monetary Policy

Figure 12: Effect of Technogy and Monetary Policy on Adoption

The environment follows Berentsen and Waller (2011). In the DM, the buyer's utility function is $\xi u(x)$, where $\xi$ is an aggregate demand shock with distribution $G$ supported on $[\underline{\xi}, \bar{\xi}]$. The realization of $\xi$ is revealed before the DM opens. At the beginning of DM, the central bank can increase or decrease money supply through lump-sum transfer or tax. It can commit to a money growth rule in the long run by undoing the operation in the CM. ${ }^{16}$ E-money follows a constant money growth rule. For simplicity, in this subsection, we assume the trading mechanism is a take-it-orleave-it offer. In addition, define $y^{*}(\xi)$ to be the efficient allocation when the state is $\xi$, i.e., $u^{\prime}\left(y^{*}(\xi)\right)=1 / \xi$. Following Berentsen and Waller (2011), one can show that the steady state equilibrium is given by

$$
\begin{aligned}
i^{m} & =\alpha_{1} \int \lambda\left(z_{\xi}^{m}, \xi\right) d G(\xi)+\alpha_{3} \int \lambda\left(z_{\xi}^{m}+z^{h}, \xi\right) d G(\xi) \\
i^{h} & =\alpha_{2} \int \lambda\left(z^{h}, \xi\right) d G(\xi)+\alpha_{3} \int \lambda\left(z_{\xi}^{m}+z^{h}, \xi\right) d G(\xi)
\end{aligned}
$$

where $z_{\xi}^{m}$ is the state-dependent real balance in the DM after the central bank

\footnotetext{
${ }^{16}$ Another way to formulate this is to have a financial market that opens before the DM and after the shock is realized. The central bank can lend money in that market to the buyers at some market interest rate. Both formulations lead to the same equations.
} 
transfer and

$$
\lambda(z, \xi)=\left\{\begin{array}{cc}
\xi u^{\prime}(z)-1 & \text { if } z \leq z^{*}(\xi) \\
0 & \text { otherwise }
\end{array}\right.
$$

$z^{*}(\xi)=y^{*}(\xi)$. The central bank uses a short-term intervention to maximize the total surplus, which is equivalent to choosing $z_{\xi}^{m}$. The optimal stabilization policy is

$$
\begin{aligned}
\left(\bar{z}_{\xi}^{m}, \bar{z}^{h}\right) & =\arg \max _{z_{\xi}, z^{h}} \alpha_{1} \int\left[\xi u \circ Y\left(z_{\xi}, \xi\right)-Y\left(z_{\xi}, \xi\right)\right] d F(\xi) \\
& +\alpha_{2} \int\left[\xi u \circ Y\left(z^{h}, \xi\right)-Y\left(z^{h}, \xi\right)\right] d F(\xi) \\
& +\alpha_{3} \int\left[\xi u \circ Y\left(z_{\xi}+z^{h}, \xi\right)-Y\left(z_{\xi}+z^{h}, \xi\right)\right] d F(\xi) \\
\text { s.t. } i^{m} & =\alpha_{1} \int \lambda\left(z_{\xi}, \xi\right) d F(\xi)+\alpha_{3} \int \lambda\left(z_{\xi}+z^{h}, \xi\right) d F(\xi), \\
i^{h} & =\alpha_{2} \int \lambda\left(z^{h}, \xi\right) d F(\xi)+\alpha_{3} \int \lambda\left(z_{\xi}+z^{h}, \xi\right) d F(\xi),
\end{aligned}
$$

where $Y(D, \xi)=D 1\left(D \leq z^{*}(\xi)\right)+z^{*} 1\left(D>z^{*}(\xi)\right)$. The optimization problem leads to the following first-order conditions:

$$
\begin{aligned}
\alpha_{1} \lambda\left(\bar{z}_{\xi}^{m}, \xi\right)+\alpha_{3} \lambda\left(\bar{z}_{\xi}^{m}+\bar{z}^{h}, \xi\right) & =\mu_{1} \alpha_{1} \lambda^{\prime}\left(\bar{z}_{\xi}^{m}, \xi\right)+\left[\mu_{1}+\mu_{2}\right] \alpha_{3} \lambda^{\prime}\left(\bar{z}_{\xi}^{m}+\bar{z}^{h}, \xi\right) \\
\alpha_{2} \lambda\left(\bar{z}^{h}, \xi\right)+\alpha_{3} \lambda\left(\bar{z}_{\xi}^{m}+\bar{z}^{h}, \xi\right) & =\left[\mu_{1}+\mu_{2}\right] \alpha_{3} \lambda^{\prime}\left(\bar{z}_{\xi}^{m}+\bar{z}^{h}, \xi\right)+\mu_{2} \alpha_{2} \lambda^{\prime}\left(\bar{z}^{h}, \xi\right),
\end{aligned}
$$

where $\mu_{1}$ and $\mu_{2}$ are the Lagrangian multipliers on the first and the second constraint. We can obtain the following result similar to Berentsen and Waller (2011).

Proposition 10 When $i^{m}>0$, the optimal stabilization policy yields $\bar{z}_{\xi}^{m}<z^{*}(\xi)$ for all $\xi$.

Proof. Without loss of generality, we can restrict $\bar{z}_{\xi}^{m} \leq z^{*}(\xi)$. Since $\partial \lambda(z, \xi) / \partial z<$ 0 for all $z \in\left[0, z^{*}(\xi)\right]$, the FOC suggests that $\alpha_{1} \lambda\left(\bar{z}_{\xi}^{m}, \xi\right)+\alpha_{3} \lambda\left(\bar{z}_{\xi}^{m}+\bar{z}^{h}, \xi\right)$ is not 0 . Because $\lambda\left(\bar{z}_{\xi}^{m}, \xi\right) \geq \lambda\left(\bar{z}_{\xi}^{m}+\bar{z}^{h}, \xi\right)>0, \lambda\left(\bar{z}_{\xi}^{m}, \xi\right)>0$. Hence, $\bar{z}_{\xi}^{m}<z^{*}(\xi)$.

If there is no stabilization policy and $\xi$ is low, buyers in type 1 transactions can consume $y^{*}(\xi)$ for sufficiently small $i^{m}$. This suggests that in general, the optimal stabilization policy yields different allocations. The stabilization policy stabilizes the 
marginal value of liquidity across states by injecting fiat money when $\xi$ is high and extracting fiat money when $\xi$ is low. It is worth noting that this type of stabilization policy does not change the value of money in the CM. However, it does change the value of transactions that are made in fiat money on average.

We use a numerical example to illustrate the effect of central bank stabilization policy on the adoption of e-money. We compute the average value of transactions in e-money in type 3 transactions across all states and divide it by the average type 3 transaction value. This can be regarded as a measure of adoption. A higher value means a higher adoption. Figure 13 plots this measure as a function of the standard error of $\xi$, which measures the size of the preference shocks. The red line depicts the value when there is no stabilization policy and the blue curve is constructed under optimal stabilization policy. The long-run growth rate currency is set to be $2 \%$. The demand shock $\xi$ has a two-point distribution with mean 1 and half probability being high and half probability being low. Now one can see that the blue curve is below the red curve when the standard error of $\xi$ is positive, which suggests that stabilization policy can reduce the adoption of e-money in type 3 transactions on average. In addition, the blue curve is decreasing in the standard error of $\xi$. This means that as the uncertainty increases, the optimal stabilization policy is more effective in reducing the adoption of e-money.

\section{Conclusion}

This paper develops a model in which e-money has advantages over fiat money in some transactions. We interpret these transactions as online transactions in which physically handing fiat money to the sellers is not possible, and using a debit or credit card requires possessing a bank account and is not anonymous. An e-money like bitcoin preserves anonymity to some degree and can be less costly. Therefore, e-money can potentially be valued and become a competitor of central-bank-issued 


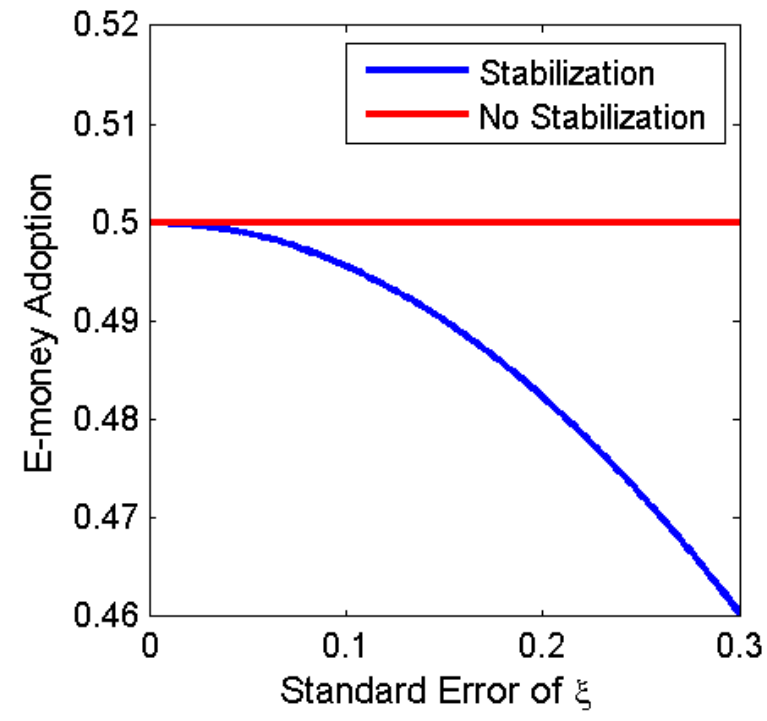

Figure 13: Ratio of Transaction Value in Fiat Money to Total Transaction Value in Type 3 Transactions

money.

In this environment, the value and adoption of e-money depends on the size of the transactions in which e-money is advantageous as well as the monetary policies of both e-money and fiat money. Existence of e-money can restrict the monetary authority's ability to raise the inflation tax. Therefore, e-money can be beneficial for less-developed countries whose monetary authorities have a tendency to over-issue fiat money. One can show that in this economy, the exchange rate between e-money and fiat money can be very volatile. Under very reasonable parameters, there exist dynamic equilibria in which the exchange rate exhibits cycles, chaotic dynamics, as well as exchange rate surges and plummets even if fundamentals are constant.

We show that privately issued e-money can lead to a monetary policy coordination issue. The optimal monetary policy is the Friedman rule for both e-money and fiat money. Under the optimal policy, the first best can be achieved. But if e-money runs a suboptimal monetary policy, the central bank may have to deviate from the Friedman rule. Since optimal policy incurs a loss, the e-money issuer may deviate 
from it even if he is benevolent. This is because the private issuer lacks the ability to finance himself through taxes or donations. If the e-money issuer aims to maximize seigniorage income, the coordination issue is more prominent. We study this in a policy-setting game. We show that the equilibrium outcome can be far away from the optimal policy. In addition, there can be multiple equilibria. Consequently, it may be beneficial to have the central-bank-issued e-money, i.e., central bank digital currency. 


\section{Appendix A: Derivations of (7) and (8)}

Notice (6) implies that

$$
\begin{aligned}
& y_{t}^{1}=\left\{\begin{array}{cc}
g^{-1}\left(\phi_{t} m_{t}\right) & \text { if } \phi_{t} m_{t}<D^{*} \\
y^{*} & \text { otherwise }
\end{array} \text { and } m_{t}^{1}=\left\{\begin{array}{cc}
m_{t} & \text { if } \phi_{t} m_{t}<D^{*} \\
D^{*} / \phi_{t} & \text { otherwise }
\end{array},\right.\right. \\
& y_{t}^{2}=\left\{\begin{array}{cc}
g^{-1}\left(\psi_{t} h_{t}\right) & \text { if } \psi_{t} h_{t}<D^{*} \\
y^{*} & \text { otherwise }
\end{array} \text { and } h_{t}^{2}=\left\{\begin{array}{cc}
h_{t}^{2} & \text { if } \psi_{t} h_{t}<D^{*} \\
D^{*} / \psi_{t} & \text { otherwise }
\end{array}\right.\right. \\
& y_{t}^{3}=\left\{\begin{array}{cc}
g^{-1}\left(\psi_{t} h_{t}+\phi_{t} m_{t}\right) & \text { if } \psi_{t} h_{t}+\phi_{t} m_{t}<D^{*} \\
y^{*} & \text { otherwise }
\end{array}\right. \\
& \phi_{t} m_{t}^{3}+\psi_{t} h_{t}^{3}=\left\{\begin{array}{cc}
\psi_{t} h_{t}+\phi_{t} m_{t} & \text { if } \psi_{t} h_{t}+\phi_{t} m_{t}<D^{*} \\
D^{*} & \text { otherwise }
\end{array} .\right.
\end{aligned}
$$

Hence, we have

$$
\begin{aligned}
& \frac{\partial y_{t}^{1}}{\partial m_{t}}=\left\{\begin{array}{cc}
\phi_{t} / g^{\prime} \circ g^{-1}\left(\phi_{t} m_{t}\right) & \text { if } \phi_{t} m_{t}<D^{*} \\
0 & \text { otherwise }
\end{array}, \frac{\partial m_{t}^{1}}{\partial m_{t}}=\left\{\begin{array}{cc}
1 & \text { if } \phi_{t} m_{t}<D^{*} \\
0 & \text { otherwise }
\end{array},\right.\right. \\
& \frac{\partial y_{t}^{2}}{\partial h_{t}}=\left\{\begin{array}{cc}
\psi_{t} / g^{\prime} \circ g^{-1}\left(\psi_{t} h_{t}\right) & \text { if } \psi_{t} h_{t}<D^{*} \\
0 & \text { otherwise }
\end{array}, \frac{\partial h_{t}^{2}}{\partial h_{t}}=\left\{\begin{array}{cc}
1 & \text { if } \psi_{t} h_{t}<D^{*} \\
0 & \text { otherwise }
\end{array},\right.\right. \\
& \frac{\partial y_{t}^{3}}{\partial m_{t}}=\left\{\begin{array}{cc}
\phi_{t} / g^{\prime} \circ g^{-1}\left(\psi_{t} h_{t}+\phi_{t} m_{t}\right) & \text { if } \psi_{t} h_{t}+\phi_{t} m_{t}<D^{*} \\
0 & \text { otherwise }
\end{array},\right. \\
& \frac{\partial y_{t}^{3}}{\partial h_{t}}=\left\{\begin{array}{cc}
\psi_{t} / g^{\prime} \circ g^{-1}\left(\psi_{t} h_{t}+\phi_{t} m_{t}\right) & \text { if } \psi_{t} h_{t}+\phi_{t} m_{t}<D^{*} \\
0 & \text { otherwise }
\end{array},\right. \\
& \frac{\partial\left(\phi_{t} m_{t}^{3}+\psi_{t} h_{t}^{3}\right)}{\partial m_{t}}=\left\{\begin{array}{cc}
\phi_{t} & \text { if } \psi_{t} h_{t}+\phi_{t} m_{t}<D^{*} \\
0 & \text { otherwise }
\end{array}\right. \\
& \frac{\partial\left(\phi_{t} m_{t}^{3}+\psi_{t} h_{t}^{3}\right)}{\partial h_{t}}=\left\{\begin{array}{cc}
\psi_{t} & \text { if } \psi_{t} h_{t}+\phi_{t} m_{t}<D^{*} \\
0 & \text { otherwise }
\end{array} .\right.
\end{aligned}
$$

Differentiate (5) with respect to $m_{t}$ and use (4) to obtain

$\frac{\partial V_{t}\left(m_{t}, h_{t}\right)}{\partial m_{t}}=\alpha_{1}\left[u^{\prime}\left(y_{t}^{1}\right) \frac{\partial y_{t}^{1}}{\partial m_{t}}-\phi_{t} \frac{\partial m_{t}^{1}}{\partial m_{t}}\right]+\alpha_{3}\left[u^{\prime}\left(y_{t}^{3}\right) \frac{\partial y_{t}^{3}}{\partial m_{t}}-\frac{\partial\left(\phi_{t} m_{t}^{3}+\psi_{t} h_{t}^{3}\right)}{\partial m_{t}}\right]+\phi_{t}$.

Substitute in the expressions for these partial derivatives and use the definition of $\lambda$ to arrive at (7). A similar derivation leads to (8). 


\section{Appendix B: Proof of Proposition 1}

The equilibrium has four possible regimes: (1) $z^{m}=z^{h}=0 ;(2) z^{m}=0, z^{h}>0$; (3) $z^{m}>0, z^{h}=0 ;(4) z^{m}>0, z^{h}>0$. The proof has two steps. We first show that given the regime, $z^{m}$ and $z^{h}$ are uniquely determined. Then we show for any set of parameters, only one of these regimes can arise.

Step 1: Obviously, in regime (1), $z^{m}$ and $z^{h}$ are uniquely determined. In regime (2), $z^{h}$ is determined by $i^{h}=\left(\alpha_{2}+\alpha_{3}\right) \lambda\left(z^{h}\right)$. Since the trading mechanism is Kalai, $\lambda$ is strictly decreasing. Therefore, there is at most one $z^{h}$ that satisfies the equation. The same argument applies to regime (3). For regime (4), the equilibrium is determined by

$$
\begin{aligned}
i^{m} & =\alpha_{1} \lambda\left(z^{m}\right)+\alpha_{3} \lambda\left(z^{m}+z^{h}\right), \\
i^{h} & =\alpha_{2} \lambda\left(z^{h}\right)+\alpha_{3} \lambda\left(z^{m}+z^{h}\right) .
\end{aligned}
$$

Equation (18) defines $z^{m}$ as a decreasing function of $z^{h}, z^{m}=Z^{m}\left(z^{h}\right)$. And if $z^{h}$ is sufficiently large, $Z^{m}\left(z^{h}\right)=\tilde{z}^{m}$, where $i^{m}=\alpha_{1} \lambda\left(\tilde{z}^{m}\right)$. Similarly, (19) defines $z^{h}$ as a decreasing function of $z^{h}=Z^{h}\left(z^{m}\right)$ and for $z^{m}$ sufficiently large, $Z^{h}\left(z^{m}\right)=\tilde{z}^{h}$ where $i^{h}=\alpha_{2} \lambda\left(\tilde{z}^{h}\right)$. The equilibrium is an $z^{m}$ such that $Z^{m} \circ Z^{h}\left(z^{m}\right)=z^{m}$. Notice that $Z^{m} \circ Z^{h}(0)=Z^{m}\left(\bar{z}^{h}\right)>0$. Otherwise, one cannot find $z^{m}>0$ and $z^{h}>0$ that satisfy both equations. In addition, $Z^{m} \circ Z^{h}\left(z^{m}\right)=\bar{z}^{m}$ for $z^{m}$ sufficiently large. Therefore, $Z^{m} \circ Z^{h}(0)>0$ and $Z^{m} \circ Z^{h}(\infty)=\bar{z}^{m}<\infty$. By continuity of $Z^{m}$ and $Z^{h}$, there exists at least one equilibrium. To see that it is unique, just notice that at the solution of $Z^{m} \circ Z^{h}\left(z^{m}\right)-z^{m}=0$, the derivative is equal in sign to $-D D$ where $D D=\alpha_{1} \alpha_{2} \lambda^{\prime}\left(z^{m}\right) \lambda^{\prime}\left(z^{h}\right)+\alpha_{1} \alpha_{3} \lambda^{\prime}\left(z^{m}\right) \lambda^{\prime}\left(z^{m}+z^{h}\right)+\alpha_{2} \alpha_{3} \lambda^{\prime}\left(z^{h}\right) \lambda^{\prime}\left(z^{m}+z^{h}\right)>0$.

Therefore, there can be at most one $z^{m}$ that solves $Z^{m} \circ Z^{h}\left(z^{m}\right)-z^{m}=0$ and uniqueness follows. Now we have accomplished step 1. 
Step 2: Obviously, if regime 1 occurs, no other regimes can occur.

Now consider regime 2. If it occurs, obviously regime 1 cannot appear in the equilibrium. Now we rule out regime 3. By definition, now we have at the equilibrium $z^{h}$

$$
\begin{aligned}
i^{h} & =\alpha_{2} \lambda\left(z^{h}\right)+\alpha_{3} \lambda\left(z^{h}\right) \\
i^{m} & >\alpha_{1} \lambda(0)+\alpha_{3} \lambda\left(z^{h}\right) .
\end{aligned}
$$

Suppose toward contradiction, there exists an $z^{m}>0$ such that

$$
\begin{aligned}
i^{h} & >\alpha_{2} \lambda(0)+\alpha_{3} \lambda\left(z^{m}\right) \\
i^{m} & =\alpha_{1} \lambda\left(z^{m}\right)+\alpha_{3} \lambda\left(z^{m}\right) .
\end{aligned}
$$

Then (20) and (22) imply that

$$
\alpha_{2} \lambda\left(z^{h}\right)+\alpha_{3} \lambda\left(z^{h}\right)>\alpha_{2} \lambda(0)+\alpha_{3} \lambda\left(z^{m}\right)
$$

Because $\lambda$ is decreasing, this means $z^{h}>z^{m}$. Similarly, (21) and (23) imply that

$$
\alpha_{1} \lambda\left(z^{m}\right)+\alpha_{3} \lambda\left(z^{m}\right)>\alpha_{1} \lambda(0)+\alpha_{3} \lambda\left(z^{h}\right)
$$

which means $z^{m}>z^{h}$. This is a contradiction. Therefore, regime 3 cannot occur. Lastly, we rule out regime 4 . Suppose that there exists $\tilde{z}^{m}$ and $\tilde{z}^{h}$ such that

$$
\begin{aligned}
i^{h} & =\alpha_{2} \lambda\left(\tilde{z}^{h}\right)+\alpha_{3} \lambda\left(\tilde{z}^{m}+\tilde{z}^{h}\right) \\
i^{m} & =\alpha_{1} \lambda\left(\tilde{z}^{m}\right)+\alpha_{3} \lambda\left(\tilde{z}^{m}+\tilde{z}^{h}\right) .
\end{aligned}
$$

Obviously, $\tilde{z}^{m}+\tilde{z}^{h}>z^{h}$. Therefore, (25) cannot hold. This rules out regime 4 . This means that under the parameters where regime 2 occurs, no other regime can occur. A similar argument holds for regime 3 and regime 4.

For the last claim, notice that if $i^{m}>\bar{\imath}^{m}$, regime (2) is an equilibrium. And by the above analysis, that is the only equilibrium. Hence, it cannot be that both 
monies are valued. The same holds if $i^{h}>\bar{\imath}^{h}$. This proves the "only if" part. For the "if" part, notice that the only regime that is possible is regime 4 . This concludes the proof.

\section{Appendix C: Proof of Proposition 2}

Take the difference of the above equations and rearrange to obtain

$$
i^{h}=\alpha_{2} \lambda\left(z^{h}\right)-\alpha_{1} \lambda\left(z^{m}\right)+i^{m}
$$

Notice $z^{m}$ is decreasing in $z^{h}$ by (19). This suggests that in equilibrium $z^{m} \leq \bar{z}^{m}$. Because $\lambda$ is decreasing, if $z^{h}>0$, we must have

$$
i^{h}=\alpha_{2} \lambda\left(z^{h}\right)-\alpha_{1} \lambda\left(z^{m}\right)+i^{m}<\alpha_{2} \lambda(0)-\alpha_{1} \lambda\left(\bar{z}^{m}\right)+i^{m}
$$

One can substitute in $\alpha_{1} \lambda\left(\bar{z}^{m}\right)+\alpha_{3} \lambda\left(\bar{z}^{m}\right)=i^{m}$ to prove the first claim. Since $\bar{z}^{m}$ is decreasing in $i^{m}$ and $\lambda$ decreasing, $d \varphi / d i^{m}>0$. If $\alpha_{2}$ increases, $\bar{z}^{m}$ stays unchanged, and hence $d \varphi / d \alpha_{2}>0$. In addition, if $\alpha_{1}$ increases, $\bar{z}^{m}$ increases, which reduces $\varphi$. Moreover,

$$
\frac{d \alpha_{3} \lambda\left(\bar{z}^{m}\right)}{d \alpha_{3}}=\lambda\left(\bar{z}^{m}\right)-\alpha_{3} \frac{\lambda\left(\bar{z}^{m}\right)}{\alpha_{3}+\alpha_{1}}>0 .
$$

Therefore, $d \varphi / d \alpha_{3}>0$. Lastly, if $z^{h}=0, d z^{h} / d i^{m}=0$. If $z^{h}>0$, applying the Cramer's rule, one can obtain

$$
\begin{aligned}
\frac{d z^{m}}{d i^{m}} & =\frac{\alpha_{2} \lambda^{\prime}\left(z^{h}\right)+\alpha_{3} \lambda^{\prime}\left(z^{m}+z^{h}\right)}{D D}<0 \\
\frac{d z^{h}}{d i^{m}} & =-\frac{\alpha_{3} \lambda^{\prime}\left(z^{m}+z^{h}\right)}{D D}>0 \\
\frac{d z^{m}}{d i^{h}} & =-\frac{\alpha_{3} \lambda^{\prime}\left(z^{m}+z^{h}\right)}{D D}>0 \\
\frac{d z^{h}}{d i^{h}} & =\frac{\alpha_{1} \lambda^{\prime}\left(z^{m}\right)+\alpha_{3} \lambda^{\prime}\left(z^{m}+z^{h}\right)}{D D}<0 \\
\frac{d z^{m}}{d \alpha_{1}} & =-\frac{\lambda\left(z^{m}\right)\left[\alpha_{2} \lambda^{\prime}\left(z^{h}\right)+\alpha_{3} \lambda^{\prime}\left(z^{m}+z^{h}\right)\right]}{D D}>0 \\
\frac{d z^{h}}{d \alpha_{1}} & =\frac{\lambda\left(z^{m}\right) \alpha_{3} \lambda^{\prime}\left(z^{m}+z^{h}\right)}{D D}<0 \\
\frac{d z^{m}}{d \alpha_{2}} & =\frac{\lambda\left(z^{h}\right) \alpha_{3} \lambda^{\prime}\left(z^{m}+z^{h}\right)}{D D}<0
\end{aligned}
$$




$$
\begin{aligned}
\frac{d z^{h}}{d \alpha_{2}} & =-\frac{\lambda\left(z^{h}\right)\left[\alpha_{1} \lambda^{\prime}\left(z^{m}\right)+\alpha_{3} \lambda^{\prime}\left(z^{m}+z^{h}\right)\right]}{D D}>0 \\
\frac{d z^{m}}{d \alpha_{3}} & =-\frac{\lambda\left(z^{m}+z^{h}\right) \alpha_{2} \lambda^{\prime}\left(z^{h}\right)}{D D}>0 \\
\frac{d z^{m}}{d \alpha_{3}} & =-\frac{\lambda\left(z^{m}+z^{h}\right) \alpha_{1} \lambda^{\prime}\left(z^{m}\right)}{D D}>0 .
\end{aligned}
$$

\section{Appendix D: Proof of Proposition 4}

Consider the case in which $\alpha_{1}=0$. If $0<i^{h}<\alpha_{2} \lambda(0)$ and $i^{m}$ sufficiently small, both monies are valued in equilibrium. One can show that

$$
\begin{aligned}
\frac{\partial \Omega\left(i^{m}, i^{h}\right)}{\partial i^{m}}= & \alpha_{2}\left[u^{\prime} \circ Y\left(z^{h}\right)-c^{\prime} \circ Y\left(z^{h}\right)\right] Y^{\prime}\left(z^{h}\right) \frac{\partial z^{h}}{\partial i^{m}} \\
& +\alpha_{3}\left[u^{\prime} \circ Y\left(z^{h}+z^{m}\right)-c^{\prime} \circ Y\left(z^{h}+z^{m}\right)\right] Y^{\prime}\left(z^{h}+z^{m}\right) \frac{\partial z^{h}}{\partial i^{m}},(26)
\end{aligned}
$$

where $z^{h}$ and $z^{m}$ are determined by

$$
\begin{aligned}
i^{m} & =\alpha_{3} \lambda\left(z^{m}+z^{h}\right), \\
i^{h} & =\alpha_{2} \lambda\left(z^{h}\right)+\alpha_{3} \lambda\left(z^{m}+z^{h}\right) .
\end{aligned}
$$

If $i^{m}=0$ and $i^{h}>0$, by (9), $z^{h}+z^{m}>D^{*}, z^{h}<D^{*}, Y\left(z^{h}+z^{m}\right)=y^{*}$ and $Y\left(z^{h}\right)<y^{*}$. Because $u^{\prime}(y)-c^{\prime}(y)>0$ for all $y<y^{*}, Y^{\prime}(z)<0$ for all $z<D^{*}$ and

$$
\frac{\partial z^{h}}{\partial i^{m}}=-\frac{1}{\alpha_{2} \lambda^{\prime}\left(z^{h}\right)}>0
$$

for all $z^{h}<D^{*}$. Then

$$
\left.\frac{\partial \Omega\left(i^{m}, i^{h}\right)}{\partial i^{m}}\right|_{i^{m}=0}=\alpha_{2}\left[u^{\prime} \circ Y\left(z^{h}\right)-c^{\prime} \circ Y\left(z^{h}\right)\right] Y^{\prime}\left(z^{h}\right) \frac{\partial z^{h}}{\partial i^{m}}>0 .
$$

Therefore, the optimal policy is $i^{m}=\hat{\imath}^{m}>0$. Then by continuity, if $\alpha_{1}$ is sufficiently close to 0 , the optimal policy involves an $i^{m}>0$.

Next, notice that if $\alpha_{1}>0$ and is sufficiently small, the optimal $i^{m}$ is strictly positive. 
Let $\underline{i}^{m}$ be the highest value of $i^{m}$ at which buyers in type 3 transactions are not constrained. Then the welfare is decreasing if $i^{m}<\underline{i}^{m}$ because when $i^{m}$ is sufficiently small, buyers are not constrained in type 3 transactions. Increasing $i^{m}$ decreases consumption only in type 1 transactions. Therefore, the optimal $i^{m}$ must be above $\underline{i}^{m}$. Notice if $i^{m}>\bar{\imath}^{m}$, the total welfare is not changing in $i^{m}$ because fiat money is not valued. Also

$$
\lim _{\Delta \downarrow 0} \frac{\Omega\left(\bar{\imath}^{m}-\Delta, i^{h}\right)-\Omega\left(\bar{\imath}^{m}, i^{h}\right)}{\Delta}=\alpha_{1}\left[u^{\prime}(0)-c^{\prime}(0)\right] Y^{\prime}(0)>0 .
$$

Therefore, lower $i^{m}$ from $\bar{\imath}^{m}$ increases welfare. As a result, the optimal monetary policy $\hat{\imath}^{m} \in\left(\underline{i}^{m}, \bar{\imath}^{m}\right)$.

Now suppose $\alpha_{1}=0$. Notice that under Kalai's solution, (26) and the results from Appendix C imply

$$
\theta \frac{\partial \Omega\left(i^{m}, i^{h}\right)}{\partial i^{m}}=\alpha_{2} \lambda\left(z^{h}\right) \frac{\partial z^{h}}{\partial i^{m}}+\alpha_{3} \lambda\left(z^{h}+z^{m}\right) \frac{\partial z^{h}}{\partial i^{m}} \simeq-\frac{\lambda\left(z^{h}\right)}{\lambda^{\prime}\left(z^{h}\right)}+\frac{\lambda\left(z^{h}+z^{m}\right)}{\lambda^{\prime}\left(z^{h}+z^{m}\right)},
$$

where $\simeq$ means equal in sign. This immediately implies that $\frac{\partial \Omega\left(i^{m}, i^{h}\right)}{\partial i^{m}}=0$ if $z^{m}=0$, which holds if $i^{m} \geq \alpha_{3} /\left(\alpha_{2}+\alpha_{3}\right) i^{h}$. If $i^{m}<\alpha_{3} /\left(\alpha_{2}+\alpha_{3}\right) i^{h}, z^{m}>0$. Notice that for all $z \geq z^{h}$

$$
\left[\frac{\lambda(z)}{\lambda^{\prime}(z)}\right]^{\prime}=\frac{\lambda^{\prime}(z)^{2}-\lambda^{\prime \prime}(z) \lambda(z)}{\lambda^{\prime}(z)^{2}}>1-\frac{\left|\lambda^{\prime \prime}(z)\right|}{\lambda^{\prime}(z)^{2}} \lambda\left(z^{h}\right) \geq 1-\frac{\left|\lambda^{\prime \prime}(z)\right|}{\lambda^{\prime}(z)^{2}} \frac{i^{h}-i^{m}}{\alpha_{2}},
$$

which is positive if $i^{h}$ is sufficiently small. This suggests $\frac{\partial \Omega\left(i^{m}, i^{h}\right)}{\partial i^{m}}>0$ because $z^{h}+z^{m}>z^{h}$

\section{Appendix E: Existence of a Pure Strategy Equilibrium in the Simultaneous Move Game}

Throughout this section, we assume that $u(y)=y^{1-\sigma} /(1-\sigma), c(y)=y^{1+\eta} /(1+\eta)$, $\alpha_{1}=0$ and $\theta=1$. We will derive conditions for the existence of a pure strategy 
equilibrium that can be easily checked numerically. To start, denote $(1+\eta) /(\sigma+\eta)$ by $\xi$. Let $i_{L}$ and $i_{H}$ satifies

$$
\begin{aligned}
1+\frac{\alpha_{2}+\alpha_{3}}{\alpha_{3}} i_{L} & =\frac{\xi+1+\sqrt{(\xi+1)^{2}-4 \xi \beta\left(1+i_{L}-\alpha_{2}\right)}}{2 \xi \beta} \\
1+\frac{\alpha_{2}+\alpha_{3}}{\alpha_{3}} i_{H} & =\frac{\xi+1+\sqrt{(\xi+1)^{2}-4 \xi \beta\left(1-\alpha_{2}-\alpha_{3}\right)}}{2 \xi \beta}
\end{aligned}
$$

and $\bar{i}_{1}^{h}$ and $\bar{i}_{2}^{h}$ satisfies

$$
\begin{aligned}
1+\bar{i}_{2}^{h} & =\frac{\xi+1+\sqrt{(\xi+1)^{2}-4 \xi \beta\left(1+i^{m}-\alpha_{2}\right)}}{2 \xi \beta}, \\
1+\bar{i}_{1}^{h} & =\frac{\xi+1+\sqrt{(\xi+1)^{2}-4 \xi \beta\left(1-\alpha_{2}-\alpha_{3}\right)}}{2 \xi \beta} .
\end{aligned}
$$

Notice that $i_{H}, i_{L}$ and $\bar{i}_{1}^{h}$ are three numbers that depend on the parameters only while $\bar{i}_{2}^{h}$ is a function of $i^{m}$. The next result charaterizes the best response function of the e-money issuer.

Lemma 11 The best response of the e-money issuer is

$$
B R_{h}\left(i^{m}\right)= \begin{cases}i_{2}^{h} & i^{m}<i_{L} \\ \frac{\alpha_{2}+\alpha_{3}}{\alpha_{3}} i^{m} & i^{m} \in\left[i_{L}, i_{H}\right] \\ i_{1}^{h} & i^{m}>i_{H}\end{cases}
$$

Proof. Given that e-money is valued, fiat money is not valued iff

$$
i^{m} \geq \alpha_{3} \lambda\left(z^{h}\right), i^{h}=\alpha_{2} \lambda\left(z^{h}\right)+\alpha_{3} \lambda\left(z^{h}\right),
$$

where $\lambda(z)=[(1+\eta) z]^{-\frac{1}{\xi}}-1$. This implies that e-money and fiat money co-exist iff $\alpha_{3} i^{h} /\left(\alpha_{2}+\alpha_{3}\right)>i^{m}$. Consequently, given $i^{m}$,

$$
\Pi^{h}\left(i^{m}, i^{h}\right)=\left\{\begin{array}{ll}
\lambda^{-1}\left(\frac{i^{h}}{\alpha_{2}+\alpha_{3}}\right)\left[1-\frac{1}{\beta\left(1+i^{h}\right)}\right] & \text { if } i^{h}<\frac{\alpha_{2}+\alpha_{3}}{\alpha_{3}} i^{m} \\
\lambda^{-1}\left(\frac{i^{h}-i^{m}}{\alpha_{2}}\right)\left[1-\frac{1}{\beta\left(1+i^{h}\right)}\right] & \text { if } i^{h}>\frac{\alpha_{2}+\alpha_{3}}{\alpha_{3}} i^{m}
\end{array} .\right.
$$


Substitute $\lambda$ into $\Pi^{h}\left(i^{m}, i^{h}\right)$ and take its derivative with respect to $i^{h}$. After some algebra, one can show that

$$
\frac{\partial \Pi^{h}\left(i^{m}, i^{h}\right)}{\partial i^{h}} \simeq\left\{\begin{array}{ll}
-\xi \beta\left(1+i^{h}\right)^{2}+(\xi+1)\left(1+i^{h}\right)-\left(1-\alpha_{2}-\alpha_{3}\right) & \text { if } i^{h}<\frac{\alpha_{2}+\alpha_{3}}{\alpha_{3}} i^{m} \\
-\xi \beta\left(1+i^{h}\right)^{2}+(\xi+1)\left(1+i^{h}\right)-\left(1+i^{m}-\alpha_{2}\right) & \text { if } i^{h}>\frac{\alpha_{2}+\alpha_{3}}{\alpha_{3}} i^{m}
\end{array} .\right.
$$

There are two roots for the first branch

$$
\begin{aligned}
\bar{i}_{1}^{h} & =\frac{\xi+1+\sqrt{(\xi+1)^{2}-4 \xi \beta\left(1-\alpha_{2}-\alpha_{3}\right)}}{2 \xi \beta}-1, \\
\underline{i}_{1}^{h} & =\frac{\xi+1-\sqrt{(\xi+1)^{2}-4 \xi \beta\left(1-\alpha_{2}-\alpha_{3}\right)}}{2 \xi \beta}-1 .
\end{aligned}
$$

Because $\beta<1$ and $1-\alpha_{2}-\alpha_{3}<1, \underline{i}_{1}^{h}<1 / \beta-1$. The first branch is strictly increasing on $\left[1 / \beta-1, \bar{i}_{1}^{h}\right]$ and decreasing if $i^{h}>\bar{i}_{1}^{h}$. Similarly, the second branch has two roots.

$$
\begin{aligned}
\bar{i}_{2}^{h} & =\frac{\xi+1+\sqrt{(\xi+1)^{2}-4 \xi \beta\left(1+i^{m}-\alpha_{2}\right)}}{2 \xi \beta}-1, \\
\underline{i}_{2}^{h} & =\frac{\xi+1-\sqrt{(\xi+1)^{2}-4 \xi \beta\left(1+i^{m}-\alpha_{2}\right)}}{2 \xi \beta}-1 .
\end{aligned}
$$

Also notice that if $i^{m}-\alpha_{2}<1 / \beta-1, \underline{i}_{2}^{h}<1 / \beta-1$ and the second branch is increasing on $\left[1 / \beta-1, \bar{i}_{2}^{h}\right]$ and decreasing afterwards. Let $i_{L}$ and $i_{H}$ satisfy

$$
\begin{aligned}
& \frac{\xi+1+\sqrt{(\xi+1)^{2}-4 \xi \beta\left(1+i_{L}-\alpha_{2}\right)}}{2 \xi \beta}=1+\frac{\alpha_{2}+\alpha_{3}}{\alpha_{3}} i_{L}, \\
& \frac{\xi+1+\sqrt{(\xi+1)^{2}-4 \xi \beta\left(1-\alpha_{2}-\alpha_{3}\right)}}{2 \xi \beta}=1+\frac{\alpha_{2}+\alpha_{3}}{\alpha_{3}} i_{H} .
\end{aligned}
$$

Obviously, $i_{H}>i_{L}>0$ are uniquely defined. Notice that $i_{L}-\alpha_{2}<1 / \beta-1$. To see this, first notice if $i_{L}-\alpha_{2}=1 / \beta-1$,

$$
\frac{\xi+1+\sqrt{(\xi+1)^{2}-4 \xi \beta\left(1+i_{L}-\alpha_{2}\right)}}{2 \xi \beta}=\frac{1}{\beta}<1+\frac{\alpha_{2}+\alpha_{3}}{\alpha_{3}} i_{L} .
$$

Because the right-hand side is decreasing in $i_{L}$ and the left-hand side is increasing in $i_{L}$, the left-hand side is smaller than the right-hand side if $i_{L}-\alpha_{2}>1 / \beta-1$. 
Therefore, $i_{L}<1 / \beta-1$ by its defnition. If $i^{m}<i_{L}, \Pi^{h}\left(i^{m}, i^{h}\right)$ is strictly increasing on $\left[1 / \beta-1, \bar{i}_{2}^{h}\right]$ and decreasing after. The unique maximizer of the profit function is $i^{h}=\bar{i}_{2}^{h}$. If $i^{m} \in\left[i_{L}, i_{H}\right], \Pi^{h}\left(i^{m}, i^{h}\right)$ is strictly increasing on $\left[1 / \beta-1, \frac{\alpha_{2}+\alpha_{3}}{\alpha_{3}} i^{m}\right]$ and decreasing if $i^{h}>\frac{\alpha_{2}+\alpha_{3}}{\alpha_{3}} i^{m}$. The unique maximizer is then $i^{h}=\frac{\alpha_{2}+\alpha_{3}}{\alpha_{3}} i^{m}$. Lastly, if $i^{m}>i_{H}$, the unique maximizer is $\bar{i}_{1}^{h}$. Then the lemma follows.

Notice that if $i^{m}$ is small, e-money and fiat money co-exist. While if $i^{m}$ is intermediate, the best response of the e-money issuer is to set $i^{h}$ just low enough to drive the fiat money out of circulation. In this region, even though fiat money is not valued and used in the economy, the central bank monetary policy is still effective as it determines $i^{h}$. Also notice that if $\alpha_{1}=0$, the best response function of the e-money issuer is continuous. Unfortunately, this is not true for the best response function of the central bank. However, under certain conditions, it is continuous on relevant regions, which is enough to guarantee existence of a pure strategy equilibrium.

Proposition 12 A pure strategy equilibrium exists if under $i^{h}=\alpha_{3} i_{L} /\left(\alpha_{2}+\alpha_{3}\right)$,

$$
\log \left(\frac{x}{1-x} \frac{\alpha_{2}}{\alpha_{3}}\right)<(1+\xi) \log \frac{\frac{x}{\alpha_{3}}+\frac{1}{i^{h}}}{\frac{1-x}{\alpha_{2}}+\frac{1}{i^{h}}}, \forall x \in\left[0, \alpha_{3} /\left(\alpha_{2}+\alpha_{3}\right)\right) .
$$

In particular, there exists an $\zeta>0$ such that $i_{*}^{h}=i$ and $i_{*}^{m}=\frac{\alpha_{3}}{\alpha_{2}+\alpha_{3}} i$ is an equilibrium for every $i \in\left[i_{L}, i_{L}+\xi\right]$.

Proof. Recall that

$$
\frac{\partial \Omega\left(i^{m}, i^{h}\right)}{\partial i^{m}} \simeq\left\{\begin{array}{cl}
-\frac{i^{h}-i^{m}}{\alpha_{2} \lambda^{\prime}\left(z^{h}\right)}+\frac{i^{m}}{\alpha_{3} \lambda^{\prime}\left(z^{h}+z^{m}\right)} & \text { if } i^{m} \leq \frac{\alpha_{3}}{\alpha_{2}+\alpha_{3}} i^{h} \\
0 & \text { if } i^{m}>\frac{\alpha_{3}}{\alpha_{2}+\alpha_{3}} i^{h}
\end{array} .\right.
$$

Substitute in the expressions of $\lambda, z^{h}$ and $z^{m}$ and rearrange to obtain that if $i^{m}<$ $\frac{\alpha_{3}}{\alpha_{2}+\alpha_{3}} i^{h}$

$$
\frac{\partial \Omega\left(i^{m}, i^{h}\right)}{\partial i^{m}} \simeq-\log \left(\frac{x}{1-x} \frac{\alpha_{2}}{\alpha_{3}}\right)+(1+\xi) \log \frac{\frac{x}{\alpha_{3}}+\frac{1}{i^{h}}}{\frac{1-x}{\alpha_{2}}+\frac{1}{i^{h}}}
$$

where $x=i^{m} / i^{h}$. If the assumption of the proposition is satisfied, $\frac{\partial \Omega\left(i^{m},,^{h}\right)}{\partial i^{m}}>0$ if $i^{h}=\frac{\alpha_{2}+\alpha_{3}}{\alpha_{2}} i_{L}$ and $i^{m}<\frac{\alpha_{3}}{\alpha_{2}+\alpha_{3}} i^{h}$. By continuity, this means that there exists $\zeta>0$ 
such that if $i^{h}=i$ for any $i \in\left[\frac{\alpha_{2}+\alpha_{3}}{\alpha_{2}} i_{L}, \frac{\alpha_{2}+\alpha_{3}}{\alpha_{2}} i_{L}+\zeta\right], i^{m}=\frac{\alpha_{3}}{\alpha_{2}+\alpha_{3}} i$ is the best response of the central bank. Furthermore, according to Lemma 11, if $i_{L}+\frac{\alpha_{3}}{\alpha_{2}+\alpha_{3}} \zeta<i_{H}$, the best response of the e-money issuer is $i^{h}=i$ if $i^{m}=\frac{\alpha_{3}}{\alpha_{2}+\alpha_{3}} i$. As a result, $i_{*}^{h}=i$ and $i_{*}^{m}=\frac{\alpha_{3}}{\alpha_{2}+\alpha_{3}} i$ is an equilibrium for any $i \in\left[i_{L}, i_{L}+\xi\right]$.

Condition (29) implies that $\Omega\left(i^{m}, i^{h}\right)$ is strictly increasing in $i^{m}$ if fiat money is valued and $i^{h}=\frac{\alpha_{2}+\alpha_{3}}{\alpha_{2}} i_{L}$. It is straightforward to check numerically because $i_{L}$ depends only on parameters. We have experimented with many sets of parameters and condition (29) always holds. Notice that it is not true that (29) holds for all $i^{h}$. In fact, $\Omega\left(i^{m}, i^{h}\right)$ may have multiple local maximizers. And the global maximizer may jump from one local maximizer to another as $i^{h}$ changes. As a result, the best response function of the central bank has discontinuities even under this simple parametrization. Interestingly, there is a continuum of equilibria where the e-money issuer sets $i^{h}$ to make fiat money just not valued. The central bank is happy with its money not being valued because it is its best policy. Intuitively, it is beneficial to have only e-money circulating because that maximizes its value. As a result, households would be able to consume more.

By continuity, Proposition 12 implies that a pure strategy equilibrium exists if $\alpha_{1}$ and $1-\theta$ are both sufficiently small and $\varepsilon$ is sufficiently small.

\section{Appendix F: Numerical Algorithms}

Numerically computing the optimal monetary policy and solving the policysetting game requires computing the equilibrium given $\left(i^{m}, i^{h}\right)$ many times. The equilibrium is defined by (12)-(13) and the selection rule that both monies are valued if possible. Difficulties arise because $\lambda$ function has a flat region and $z^{m}, z^{h}$ enters the equations in a non-linear and non-separable way. It is not practical to directly apply existing numerical methods for solving equations or for optimization. To address this problem, we develop a new fast and stable algorithm to solve for 
the equilibrium given $\left(i^{m}, i^{h}\right)$. This algorithm exploits features of the equilibrium condition and does not involve any numerical optimization. Therefore, it is very fast and stable. The algorithm is based on two observations.

First, numerically solving one equation with one unknown can reduce to an interpolation problem. For example, if only the fiat money is valued, solving the equilibrium reduces to solving $i^{m}=\left(\alpha_{1}+\alpha_{3}\right) \lambda\left(z^{m}\right)$. Define

$$
\begin{aligned}
\boldsymbol{Z} & =\left(z_{1}, z_{2}, \cdots, z_{n}\right) \text { with } 0=z_{1}<z_{2}<\cdots<z_{n}=d^{*} \\
\Lambda & =\left(\lambda\left(z_{1}\right), \lambda\left(z_{2}\right), \cdots, \lambda\left(z_{n}\right)\right)
\end{aligned}
$$

The solution can be approximated by interpolation, i.e., if $\lambda\left(z_{k}\right) \leq i^{m} /\left(\alpha_{1}+\alpha_{3}\right) \leq$ $\lambda\left(z_{k+1}\right)$

$$
z^{m} \approx z_{k}+\frac{z_{k+1}-z_{k}}{\lambda\left(z_{k+1}\right)-\lambda\left(z_{k}\right)}\left(\frac{i^{m}}{\alpha_{1}+\alpha_{3}}-\lambda\left(z_{k}\right)\right) .
$$

This is much faster than numerically solving the equation if we need to do it many times for different $i^{m}$. This is because we only need to compute $\Lambda$ once and the interpolation algorithm is very efficient. This observation allows us to quickly evaluate whether both monies can be valued using Proposition 1.

Second, if both monies are valued, the equilibrium condition reduces to

$$
\begin{aligned}
i^{m} & =\alpha_{1} \lambda\left(z^{m}\right)+\alpha_{3} \lambda\left(z^{m}+z^{h}\right) \\
i^{h} & =\alpha_{2} \lambda\left(z^{h}\right)+\alpha_{3} \lambda\left(z^{m}+z^{h}\right) .
\end{aligned}
$$

The complication here is that $z^{m}$ and $z^{h}$ enter both equations in a non-separable way. But we can take the difference of these two equations to obtain separability:

$$
\begin{aligned}
i^{m} & =\alpha_{1} \lambda\left(z^{m}\right)+\alpha_{3} \lambda\left(z^{m}+z^{h}\right) \\
\alpha_{2} \lambda\left(z^{h}\right) & =i^{h}-i^{m}+\alpha_{1} \lambda\left(z^{m}\right) .
\end{aligned}
$$

The second equation defines $z^{h}$ as a function of $z^{m}: z^{h}=\Phi\left(z^{m}\right)$. This function can be easily calculated on a grid using interpolation if $\lambda$ is monotone. For any $z \in \boldsymbol{Z}$, 


$$
\text { if } \begin{aligned}
\lambda\left(z_{k}\right) \leq & {\left[i^{h}-i^{m}+\alpha_{1} \lambda\left(z^{m}\right)\right] / \alpha_{2} \leq \lambda\left(z_{k+1}\right), } \\
& \Phi(z) \approx z_{k}+\frac{z_{k+1}-z_{k}}{\lambda\left(z_{k+1}\right)-\lambda\left(z_{k}\right)}\left[\frac{i^{h}-i^{m}+\alpha_{1} \lambda\left(z^{m}\right)}{\alpha_{2}}-\lambda\left(z_{k}\right)\right] .
\end{aligned}
$$

Notice $\Phi$ is increasing in $z$. If we substitute $z^{h}$ by $\Phi\left(z^{m}\right)$ in $(30)$, the right-hand side is monotone in $z^{m}$. Therefore, we can again apply an interpolation method to compute approximately the equilibrium $z^{m}$ and then $z^{h}$ follows easily since we have already computed the $\Phi$ function.

\section{Algorithm for solving equilibrium given $\left(i^{m}, i^{h}\right)$}

1. Check whether there exists an equilibrium in which both monies are valued using Proposition 1 and the method described above for one equation with one unknown. If there does not exist such an equilibrium, then the equilibrium is the solution for the one equation with one unknown. If such an equilibrium exists proceed to 2 .

2. Solve (30) and (31) using the method described above for the equilibrium. 


\section{References}

[1] S. Aruoba, G. Rocheteau and J. Waller (2007) "Bargaining and the Value of Money," Journal of Monetary Economics 54, 2636-2655.

[2] B. Biais, C. Bisière, M.Bouvard, and C. Casamatta (2018) "The Blockchain Folk Theorem," TSE Working Paper, no. 17-817.

[3] A. Berentsen and C. Waller (2011) "Price Level Targeting and Stabilization Policy", Journal of Money, Credit, and Banking 43, 559-80.

[4] G. Camera, B. Craig and C. Waller (2004) "Currency Competition in a Fundamental Model of Money" Journal of International Economics 62(2), 521-544.

[5] G. Camera and J. Winkler (2003) "International Monetary Trade and the Law of One Price" JME 50(7), 1531-1553.

[6] R. Chang (1994) "Endogenous Currency Substituion, Inflationary Finance, and Welfare," JMCB, 903-916.

[7] P. Chiappori, P. Geoffard and R. Guesnerie (1992) "Sunspot Fluctuations around a Steady State: the Case of Multidimensional, One-Step Forward Looking Economic Models," Econometrica 60, 1097-1162.

[8] M. Coles and A. Muthoo (2003) "Bargaining in a Non-Stationary Environment," Journal of Economic Theory 109, 70-89.

[9] B. Craig and C. Waller (2000) "Dual-Currency Economies as Multiple-Payment Systems," Federal Reverve Bank of Cleveland Economic Review 36, 2-13.

[10] E. Curtis and C. Waller (2000) "A Search Theoretic Model of Legal and Illegal Currency," Journal of Monetary Economics 45, 155-184.

[11] R. Dutta (2012) "Bargaining with Revoking Costs," Games and Economic Behavior 71, 114-153.

[12] M. Engineer (2000) "Currency Transaction Costs and Competing Currencies," Journal of International Economics 52, 113-136.

[13] J. Fernández-Villaverde and D. Sanchez (2016) "Can Currency Competition Work?", Working Paper. 
[14] Geromichalos and Herrenbrueck (2016) "Monetary Policy, Asset Prices, and Liquidity in Over-the-Counter Markets," JMCB 48(1), 35-79.

[15] Geromichalos and Herrenbrueck (2016) "The Strategic Determination of the Supply of Liquid Assets," Working Paper.

[16] Geromichalos and Herrenbrueck (2017) "A Tractable Model of Indirect Asset Liquidity," Journal of Economic Theory 168, 252-260.

[17] H. Han (2015) "Over-the-Counter Markets, Intermediation and Monetary Policies," Working Paper.

[18] C. He, R. Wright and Y. Zhu (2015) "Housing and Liquidity," Review of Economic Dynamics 18(3), 435-455.

[19] A. Head and S. Shi (2003) "A Fundamental Theory of Exchange Rates and Direct Currency Trades," Journal of Monetary Economics 50, 1555-1591.

[20] J. Hendrickson, T. Hogan, W. Luther (2016) " The Political Economy of Bitcoin," Economic Inquiry 54, 925-939.

[21] G. Huberman, Jacob Leshno and Ciamac Moallemi (2017) "Monopoly Without a Monopolist: An Economic Analysis of the Bitcoin Payment System," Mimeo.

[22] R. Lagos and R. Wright (2003) "Dynamics, Cycles, and Sunspot Equilibria in 'Genuinely Dynamic, Fundamentally Disaggressive' models of Money," Journal of Economic Theory 109, 156-171.

[23] R. Lagos and R. Wright (2005) "A Unified Framework of Monetary Theory and Policy Analysis," Journal of Political Economics 113, 463-484.

[24] R. Lagos and S. Zhang (2018) "On Money As a Medium of Exchange in NearCashless Credit Economies," Mimeo.

[25] B. Lester, A. Postlewaite, R. Wright (2012) "Information, Liquidity, Asset Prices, and Monetary Policy". Review of Economic Studies 79, 1209-1238.

[26] Y. Li and Y. S. Li (2013) "Liquidity and Asset Prices: A New Monetarist Approach," Journal of Monetary Economics 60(4), 426-438. 
[27] Y. Li and A. Matsui (2009) "A Theory of International Currency: Competition and Discipline," Journal of the Japanese and International Economies 23, 407426.

[28] Q. Liu and S. Shi (2010) "Currency Areas and Monetary Coordination," International Economic Review 51(3), 813-846.

[29] C. Kahn (2013) "Private Payment Systems, Collateral, and Interest Rates," Annals of Finance 9(1), 83-114.

[30] A. Martin (2006) "Endogenous Multiple Currencies," Journal of Money, Credit, and Banking 38, 245-262.

[31] B. Ravikumar and N. Wallace (2002) "A Benefit of Uniform Currency," MPRA Paper No. 22951.

[32] G. Rocheteau, R. Wright and X. Xiao (2016) "Open Market Operations," Working Paper.

[33] T. Saito (2014) "Bitcoin: A Search-Theoretic Approach," International Journal of Innovation in the Digital Economy 6, 52-71.

[34] L. Schilling and H. Uhlig (2018) "Some Simple Bitcoin Economics," Mimeo.

[35] A. Trejos (2003) "International Currencies and Dollarization," Evolution and Procedures in Central Banking, 147.

[36] A. Trejos and R. Wright (1996) "Search-Theoretic Models of International Currency," Federal Reserve Bank St. Louis Review 78, 117-132.

[37] V. Venkateswaran and R. Wright (2013) "Pledgability and Liquidity: A New Monetarist Model of Financial and Macroeconomic Activity," NBER Macroeconomics Annual 28, 227-270.

[38] S. Williamson (2012) "Liquidity, Financial Intermediation, and Monetary Policy in a New Monetarist Model," American Economic Review 102, 2570-2605.

[39] R. Wright and A. Trejos (2001) "International Currency," Adv. Macroecon, 1.

[40] R. Wright and Y. Wong (2014) "Buyers, Sellers, and Middlemen: Variation on Search-Theoretic Themes," International Economic Review 55, 375-397. 
[41] M. Uribe (1997) "Hysteresis in a Simple Model of Currency Substitution," Journal of Monetary Economics 40, 185-202.

[42] R. Zhou (1997) "Currency Exchange in a Random Search Model," Review of Economic Studies 84, 289-310.

[43] C. Zhang (2014) "An Information-Based Theory of International Currency," Journal of International Economics 93, 286-301.

[44] Y. Zhu (2018) "A Note on Simple Strategic Bargaining for Models of Money or Credit", Journal of Money, Credit and Banking, forthcoming. 